\title{
Cyclic DSS tests for the evaluation of stress densification effects in liquefaction assessment
}

\author{
A. VIANA DA FONSECA*, M. SOARES*, FOURIE, A.B.** \\ *University of Porto, Dep. Civil Eng., Porto, Portugal, viana@fe.up.pt, smarisacsoares@gmail.com \\ ** University of Western Australia, School Civil, Environmental and Mining Eng., WA, Australia, \\ andy.fourie@uwa.edu.au
}

\begin{abstract}
To evaluate the stress correction factor for the Cyclic Resistance Ratio ("CRR") under cyclic loading with principal stress rotation, 86 Cyclic Direct Simple Shear (CDSS) tests were performed on two sands, one from Ain Beniam, in Alger, Algeria, and another from Coimbra, Portugal. These sands have distinctive grain shapes and size distributions and were tested with various relative densities and under different initial effective confining stresses. The results of the tests performed with zero initial static shear stress - therefore with the static shear stress factor Ka equal to one - indicate that the values of confining stress level correction factor, $\mathrm{K} \sigma$, as currently recommended, seem to underestimate the cyclic resistance.
\end{abstract}

KEYWORDS: cyclic liquefaction, cyclic DSS, densification effects, Cyclic Resistance Ratio

\section{Introduction}

Evaluating soil liquefaction in terms of applied mechanics principles is important to facilitate analysing these events numerically. Liquefaction remains as one of the most difficult phenomena to assess, as it is highly sensitive to a number of factors, such as void ratio or relative density, cementation, overconsolidation, at rest confining stress and prevailing in-situ static shear stresses, induced stress path, fabric, etc. Many of these factors vary from soil to soil, necessitating the study of the way they change with soil grains shape and sphericity.

Cyclic resistance is commonly determined in the laboratory at a single value of the effective confining stress in triaxial tests (usually $100 \mathrm{kPa}$ ) with no initial static shear stress (i.e. starting from an isotropic stress state). This is then modified by multiplying empirical factors $K_{\sigma}$ and $K_{\alpha}$, to take into account the stress level and the static shear stress on the horizontal plane prior to cyclic horizontal shear action, respectively. However, authors like Sivathayalan and $\mathrm{Ha}$ [1] tend to incorporate oriented specific fabric, which can distinguish different soils behaviour according to more or less regular particle shape orientations, by incorporating this effect in the factor $\mathrm{K}_{\alpha}$. If these factors are determined using a limited range of soils, using only specific experimental devices and techniques, such as axisymmetric cyclic triaxial cells, their representativeness is limited. Therefore, solutions to estimate $\mathrm{K}_{\sigma}$, like those presented by Hynes and Olsen [2], are 
typically conservative, but recommended in practice.

For triaxial tests (Tx), the cyclic resistance ratio "CRR" of sand is expressed, as defined by Tokimasu and Uchida [3], by $\tau_{\mathrm{CYC}} / \sigma_{3 \mathrm{C}}^{\prime}$, and in simple shear, as defined by Peacock and Seed [4], by $\tau_{\mathrm{CYC}} / \sigma_{\mathrm{VC}}$, where $\tau_{\mathrm{CYC}}$ is the cyclic shear stress amplitude, $\sigma_{3 \mathrm{C}}^{\prime}$ is the initial effective minor confining stress $(\mathrm{Tx})$ and $\sigma_{\mathrm{VC}}^{\prime}$ is the initial vertical effective stress in direct simple shear tests (DSS or SS). Usually the reference states are: in a cyclic triaxial test, the initial state is an isotropic consolidation stress of $100 \mathrm{kPa}$; and, in simple shear test, a vertical confining stress of $100 \mathrm{kPa}$ with no initial static shear stress on the horizontal plane, although the restraint provided by the rings may induce a $\mathrm{K}_{0}$ anisotropy due to Teflon coated stacked rings induced confinement.The CRR is then multiplied by 0.9 , the correction factor accounting for the earthquakes multidirectional shaking effect (Kramer [5]), in order to obtain the $\mathrm{CRR}_{\text {field. }}$.

There are several publications studying separately the influence of confining stress and static shear stress on cyclic liquefaction (Vaid and Chern[6]; Vaid and Sivathayalan[7]; Vaid et al. [8]). More recently Sivathayalan and $\mathrm{Ha}$ [1] pointed out that both $\mathrm{K}_{\sigma}$ and $\mathrm{K}_{\alpha}$ should not be taken into account separately, since both factors are a "reflection of the effects of various parameters on the cyclic shear resistance" (quoted from Sivathayalan and Ha [1]). In Figure 1a), from Vaid and Sivathayalan [7], it can be seen that the effect of increasing confining stress on the reduction in cyclic resistance is much smaller than currently considered, with the effect being most pronounced at higher relative densities.

In the present study, Direct Simple Shear Tests (DSS) were performed on two different sands, one from Ain Benian, in Alger, Algeria, and another from Coimbra, in Portugal, in order to infer the influence of the confining stress level on CRR, under constant static shear stress factor $\left(K_{\alpha}\right.$ $=1$ ), when principal stress rotation occurs.

\section{Soil granulometry and mineralogy}

Sand from Ain Benian

In the scope of liquefaction risk assessment evaluation, extensive laboratory studies have been completed on a sand from Ain Beniam, involved in well documented liquefaction events during the Bourmèdes earthquake that occurred in 2003 (Viana da Fonseca et al. [9]). Several conditions of density, with initial confining stresses of 100 and $300 \mathrm{kPa}$, were tested in a Cyclic Direct Simple Shear Device (DSS).

The soil is a siliceous medium sand with effective diameters of $D_{10}=0.2 \mathrm{~mm}, D_{30}=0.26 \mathrm{~mm}$, $D_{60}=0.35 \mathrm{~mm}$ and $D_{100}=0.85 \mathrm{~mm}$ (corrected over those published in Viana da Fonseca and Soares [10]). The coefficients of uniformity and shape are respectively $C_{U}=1.76$ and $C_{C}=0.97$, revealing poorly graded sand (Figure 2). The mean grain size, $D_{50}$, is about $0.31 \mathrm{~mm}$ and the 
specific gravity, Gs, is 2.69. The values of the maximum and minimum void ratio, determined by ASTM standards, are respectively: $e_{\max }=0.89$ and $e_{\min }=0.531$. Algeria Sand is predominantly quartz sand with a minimal amount of feldspars. As can be seen in Figure 2, the grain shapes are generally relatively spherical.

Coimbra Sand

In Portugal, due to past earthquakes, such as the 1755 Lisbon Earthquake, Coimbra's region has been identified as a region with several alluvial sandy deposits susceptible to liquefaction. This sand is one of the soils studied in a common research program between the Universities of Porto, Coimbra and Technical University of Lisbon. It is a predominantly quartz sand prepared artificially from a quarry in order to obtain a gradation between the sieves no. $10(2 \mathrm{~mm})$ and no. $200(0.075 \mathrm{~mm})$ of ASTM series, having effective diameters of $D_{10}=0.19 \mathrm{~mm}, D_{30}=0.32$ $\mathrm{mm}, D_{60}=0.4 \mathrm{~mm}$ and $D_{100}=1 \mathrm{~mm}$. The coefficients of uniformity and shape are respectively $C_{U}$ $=2.13$ and $C_{C}=1.37$, being also a poorly graded sand (Figure 2). The mean grain size, $D_{50}$, is about $0.36 \mathrm{~mm}$ and the specific gravity, $\mathrm{Gs}$, is 2.66 . The minimum and maximum void ratios are $e_{\min }=0.48$ and $e_{\max }=0.81$, respectively, and the grains are generally angular to sub-angular (see Figure 2).

The effect of the initial confining stress was studied by varying their values between 100, 300 and $500 \mathrm{kPa}$, in a DSS in the geotechnical laboratory at the University of Western Australia, changing the void ratio in order to cover a good range of densities.

\section{Preparation of specimens for mechanical tests and testing conditions}

\subsection{Specimen preparation}

To study the influence of principal stress rotation, a set of 86 DSS tests were performed on specimens of $72 \mathrm{~mm}$ diameter and $38 \mathrm{~mm}$ height, prepared by moist tamping with a water content of $5 \%$ (details in Viana da Fonseca \& Soares [10]). Among other techniques, moist tamping was chosen as it allows the testing of specimens with a wide range of void ratio, with satisfactory uniformity [11].

The tests are not conventionally undrained, since there is no monitoring of pore pressures, but they are constant volume tests. As discussed by Reyno et al [12], this is an equivalent condition in the simple shear apparatus. Therefore, it was decided to perform tests with and without water, saturated or dry, inside the shear box where the specimen is contained (see fig. 3 and table 1). Afterwards all tests were plotted and, as expected, a convergence was found, as was previously found by Finn et al [13]. 


\subsection{Testing conditions}

As mentioned, for all the tests, the initial specimen height was measured using a caliper, after placing the cap on the top of the specimen confined inside a rubber membrane and Teflon coated stacked rings. When positioned inside the DSS machine, vertical displacements were measured during consolidation using an external LVDT. During the direct shear test, constant volume conditions were assured.

A summary of the tests performed with the cyclic DSS device is given in Table 1. The table includes not only the relative density $\left(D_{r}\right)$ and void ratio at the end of consolidation (e), but also the initial void ratio after preparing the specimen $\left(e_{0}\right)$. The same target void ratio at three different degrees of compactness (loose, medium, dense) was pursued for all specimens; however, due to differences in the initial measurements and subsequent volume variations during consolidation, this was not totally guaranteed.

\section{Confining stress effect on cyclic liquefaction}

\subsection{Procedures}

The DSS device used to perform the tests, a "Shear Trac II" developed at the Norwegian Geotechnical Institute (NGI) (see Figure 3), is a widely known universal shear system which allows consolidation, monotonic and cyclic simple shear. Prior to testing, the soil specimen was confined inside a rubber membrane and Teflon coated stacked rings, before fixing it in the shear box. As the Teflon coated stacked rings create rigid boundaries when vertical confining stress is applied, mandatorily an anisotropic confinement is applied. However, and for analysis purposes for DSS, even though there is a $\mathrm{K}_{0}$ initial condition naturally imposed by the Teflon coated stacked rings, in this kind of device the $K_{0}$ effect is only taken into account if an initial static shear stress on the horizontal plane is applied prior to the cyclic shear. However, during this study all tests were performed without the application of initial static shear stress (i.e., $\tau$ $\mathrm{av}=0)$.

Tests are constant volume by adjusting the vertical load and, as described previously by many authors (e.g. Finn et al. [13]), it can be performed on dry, almost wet or saturated conditions as it does not interfere with cyclic resistance. This was confirmed during this study.

\subsection{Liquefaction Criteria}

Simple shear specimens were deemed to have liquefied when a single amplitude shear strain exceeded $3.75 \%$ and/or the specimen reached a zero vertical effective stress after 15 cycles, which represents an earthquake magnitude of 7.5 under the revised Idriss scaling factors (Idriss \& Boulanger [14]). This single amplitude shear strain is equivalent to $2.5 \%$ of single amplitude axial strain in a cyclic triaxial test. Zero vertical effective stress was considered to be reached when the vertical force was near to $10 \mathrm{~N}$, not allowing the axial strain to be higher than $0.3 \%$ and 
giving a minimum acceptable volumetric strain. The axial strain in fact is not kept perfectly constant during the test, having a minimal decrease of between 0.1 and $0.3 \%$, which corresponds to an insignificant change in volume. Seed et al. [15] firstly established $K_{M}$ as an earthquake magnitude correction factor to a reference earthquake magnitude of 7.5. This resulted from the inapplicability of the boundaries between liquefaction and non-liquefaction regions on CRR plots for magnitudes other than 7.5 (Youd et al. [16]). In order to have a comprehensive analysis, comparable with the studies previously done by Hynes and Olsen [2], and Idriss and Boulanger [14] for $K_{\sigma}$, the same earthquake magnitude scaling factor was adopted."

\subsection{Results}

During this study it was observed that both Ain Beniam and Coimbra sand exhibited a higher cyclic resistance at higher relative densities for all confining stresses tested. The rate of increase in cyclic resistance with relative density was observed to be higher for lower confining stresses, as the distance between the resistance curves decreases with increasing vertical confining stress (Figures 4 and 5).

On the other hand, and unlike most cyclic responses observed by other authors in others sands, both these sands exhibit a less contractive tendency due to stress densification which surpasses the contractive tendency due to the increase in confining stress. This densification process is believed to be associated with potential fabric changes during principal stress rotation that occurs during shearing in the DSS.

Both sands have a slightly higher cyclic resistance for the confining stresses tested above $100 \mathrm{kPa}$, (Figures 4 and 5). For Coimbra sand, this less contractive behaviour is more pronounced for lower relative densities than for higher relative densities, as it exhibits a higher CRR for higher confining stresses. Yet for Coimbra sand this effect seems to disappear for higher relative densities $\left(D_{r}>60 \%\right)$ as the undrained cyclic resistance curves seem to merge into a unique curve (Figure 5). On the other hand Ain Beniam sand exhibits, with increasing relative density, an increasing cyclic resistance for higher confining stresses (Figures 4 and 12). Figures 6 and 7 which correlate the CRR with the relative density (after consolidation), allow a better comparison, as the cyclic curves are located above the line for higher confining stresses, proving that for the same void ratio (after consolidation), soil specimens have higher cyclic resistance for higher initial confining stresses. A separation of the number of cycles was needed, as few tests have exactly the same number of cycles to trigger liquefaction.

Data for stress-strain, stress-path and excess pressure, with and without normalization, was plotted for tests with similar void ratios and number of cycles to liquefaction. Figures 8 to 11 were included to corroborate what was previously concluded from Figures 6 and 7. For an almost identical initial void ratio, tests with a higher confining stress seem to be less contractive, since the normalized excess pressure is slightly higher for lower confining stresses. The relative 
density differences of 2 3\% found between the compared tests are not sufficient to explain the observed differences. As these findings are not consistent with the frameworks which correct the effect of the initial confining stress, $\mathrm{K}_{\sigma}$, assuming a higher contractiveness for higher confining stresses, for a same void ratio, it is postulated the existence of a second order factor that conditions this behavior, namely rearrangement of the soils due to principal stress rotation during shearing in the simple shear apparatus.

Despite the DSS tests not having exactly the same initial void ratio (i.e. void ratio after consolidation), tests were grouped in order to be more easily compared. Results were compared in groups of tests having similar void ratios. Producing specimens having exactly similar void ratios and number of cycles to liquefaction was not achieved. Nevertheless, the method of grouping was considered legitimate and can be corroborated with results shown in Figures 6 and 7, where tests that had the same, or similar, void ratios and number of cycles to achieve $3.75 \%$ shear strain or zero vertical stress, are compared. In these figures there is an indication that tests on specimens with the same initial void ratio tested with a lower initial confining stress often exhibit a higher contractiveness. Furthermore, when exploring the effect of confining stress, the target void ratios at higher confining stresses were higher than at lower stresses, with the expectation of a greater contractive tendency; this was not observed. The implication of these findings is that the $\mathrm{K}_{\sigma}$ values proposed by Hynes \& Olsen [2], and even those proposed more recently by Idriss \& Boulanger [14], may underestimate the cyclic resistance for both the soils tested in this study when principal stress rotation occurs (Figure 12).

\subsection{Discussion}

Wijewickreme et al. [17] reported an increasing CRR for loose Fraser River sand with increasing initial vertical confining stress, for specimens formed with the same energy, as can be seen in Figure 13. Despite not having exactly the same relative density, the small change in relative density that occurs when the confining stress is increased is unlikely to offset the large decrease in CRR implied by existing correction factors, such as those in Figure 12. The observed behaviour was explained by the authors as a densification effect created by the sample reconstitution method. As stated by Wijewickreme et al [17] "for the air-pluviated sand the gain in CRR due to stress densification exceeds the potential reduction in CRR arising from increased $\sigma_{v}^{\prime}$ ". Additionally, Al-Tarhouni et al [18] found, while studying the behavior of gold tailings, that regardless of the initial confining stress, the same number of cycles was required to induce liquefaction, for a given void ratio. Following the same ideology, for both Algeria and Coimbra sand, the sample reconstitution method may have a densification effect that surpasses the potential reduction in CRR arising from increased $\sigma_{v}^{\prime}$.

The work presented in this paper concentrated on using a DSS apparatus because, unlike the triaxial test, it is not restricted in the orientation of the principal stress directions. As observed by Jefferies and Been [19] principal stress rotations "can move the stress point further into the yield 
surface until further yielding would only be triggered on the opposite side of the yield surface" and "the yield surface reflects the mobilization of particle contacts at a micromechanical level". Furthermore, according to De Gennaro et al, [20] and also supported by Papadimitriou and Bouckovalas[21], "fabric evolution during cycles" might occur. All of these observations point to the value of investigating liquefaction susceptibility using equipment other than the triaxial test (the latter of course still has a valuable place in experimental evaluation of liquefaction). As both fabric evolution and particle contacts differ from soil to soil, due to differing grain shape and roughness, it is likely that different soils may have distinctly different undrained cyclic shear responses.

It should also be pointed out that for Coimbra sand the cyclic resistance curves are more or less parallel to each other, independent of the initial vertical confining stress (Figure 5). On the other hand, Ain Beniam sand has cyclic resistance curves that are approximately parallel to one another when varying the relative density for the same confining stress (Figure 4). The physical meaning of this behaviour may be associated with the intrinsic fabric of each soil induced by moist tamping preparation, as the differences in the cyclic resistances are not the same for both sands. Furthermore, for Ain Beniam sand, for the number of cycles less than 3, the resistance is higher for lower confining stresses, similar to other soils in the cited references. From these observations it can be speculated that fabric induced by specimen preparation method, plus changes in fabric that occur with plastic strain accumulation during the test, have an influence on the response to cyclic loading. Clearly this suggestion requires further investigation.

Finally, it is suggested that investigations of $\mathrm{K}_{\sigma}$ should not consider only the effect of initial confining stress, but recognise the potential influence of fabric that is induced by specimen reconstitution technique and/or rotation of principal stresses, such as can be better investigated in a DSS apparatus than a triaxial apparatus.

\section{Conclusions}

The primary conclusion from the present work is that the effect of confining stress on cyclic resistance for cohesionless soils is not as clear as has been presented in the literature. In fact, it seems that, at least for both sands tested in this work, contractiveness does not increase with increasing confining stress. Potential densification effects aside, an additional contributing factor is suggested as being fabric rearrangement during principal stress rotation. Previously Vaid et al. [8] also pointed out that the confining stress for Fraser River sand at the loosest states, in triaxial conditions, "had little effect" on liquefaction resistance, whereby changes in $\mathrm{K}_{\sigma}$ were very low.

Although for the Algeria sand the distance between the cyclic resistance curves was greater for higher relative densities (for the number of cycles to failure higher than 3 ), meaning that cyclic 
undrained shear resistance is higher for lower confining stresses, in the case of Coimbra sand the distance between the lines decreases and they almost converge with increasing confining stress (Figures 4, 5 and 12). The results presented in this paper support conclusions of other workers (such as Wijewickreme et al [17] that the CRR gain is a result of the densification effect created by the sample reconstitution and consolidation method, which surpasses the $\sigma_{v}$ veffect. Additionally, changes in specimen fabric with plastic strain accumulation during a cyclic loading test also contribute to observed differences in cyclic response.

Regardless of the differences in the actual $\mathrm{K}_{\sigma}$ values, and those obtained in this study (even when they are approximately unity), $f$ these differences are too big to be neglected despite being on the safe side. In Figure 1, from Vaid and Sivathayalan [7] and Vaid et al [8], it can be seen that the effect of increasing confining stress on the reduction in cyclic resistance is much smaller than currently considered, varying according to the type of test device.

\section{Acknowledgments}

This work in FEUP was supported by FCT through the project PTDC/ECM/103220/2008, financed by QREN, the European Communion Operational Program for Competitive Factors COMPETE.

[1] S. Sivathayalan e H. D., "Effect of static shear stress on the cyclic resistance of sands on simple shear loading," Canadian Geotechnical Jounal, vol. 48, pp. 1471-1484, 2011.

[2] M. E. Hynes e R. S. Olsen, "Influence of confining stress on liquefaction resistance.," em Proceedings International Workshop on Physics and Mechanics of Soil Liquefaction, Balkema, Rotterdam, Netherlands, 1999.

[3] K. Tokimatsu e A. Uchida, "Correlation between liquefaction resistance and shear wave velocity," Soils and Foundations, vol. 30 (2), pp. 33-42, 1990.

[4] W. H. Peacock e H. B. Seed, "Sand liquefaction under cyclic loading simple shear conditions," Journal of Soil Mechanics and Foundations Division, ASCE, vol. 99 SM12, pp. 1179-1184, 1968.

[5] S. L. Kramer, Geotecnical Earthquake Engineering, Upper Saddle, New Jersey, USA: Prentice Hall, Inc., 1996.

[6] Y. P. Vaid e J. C. Chern, "Cyclic and monotonic undrained response of sands," em In Advances in the Art of Testing Soils under Cyclic Loading Conditions, Proceeding of the ASCE Convention, Detroit, USA, 1985. 
[7] Y. P. Vaid e S. Sivathayalan, "Static and cyclic liquefaction potential of Fraser Delta sand in simple shear and triaxial tests," Canadian Geotechnical Journal, vol. 33, pp. 281-289, 1996.

[8] Y. P. Vaid, J. D. Stedman e S. Sivathayalan, "Confining stress and static shear effects in cyclic liquefaction," Canadian Geotechnical Journal, vol. 38, pp. 580-591, 2001.

[9] A. Viana da Fonseca, A. Rocha e G. Tahar, "Liquefaction assessment charts on state and waves' velocities from static and cyclic triaxial tests on "Les Dunes" sands from Algier," em 5th International Conference on Earthquake and Geotechnical Engineering, Pub in $C D, N$. LACFO, Santiago, Chile, 2011.

[10] A. Viana da Fonseca e M. Soares, "Effect of principal stress rotation on cyclic liquefaction," em Second International Conference on Performance-Based Design in Earthquake Geotechnical Engineering CD-ROM: Art. N. 3.08, Taormina, Italy, 2012.

[11] K. Ishihara, Soil behavior in earthquake geotechnics, New York, USA: Oxford Universty Press, 1996.

[12] A. R. Reyno, D. W. Airey e H. A. Taiebat, "Influence of height and boundary conditions in simple shear tests," em Proceedings of Frontiers in Offshore Geotechnics: ISFOG, Perth, Australia, 2005.

[13] W. D. Finn, Y. P. Vaid e S. K. Bhatia, "Constant volume cyclic simple shear testing," em Proceedings on Second International Conference on Microzonation for Safer Construction, Vol.II, California, USA, 1978.

[14] I. M. Idriss e R. W. Boulanger, "Semi-empirical procedures for evaluations liquefaction potential during earthquakes," em Proceedings of the 11thICSDEE \& 3rdICEGE, Berkeley, USA, 2004.

[15] H. B. Seed, I. M. Idriss e I. Arango, "Evaluation of liquefaction potential using field performance data," Journal of Geotechnical Engineering, ASCE, vol. 109 (3), pp. 458-482, 1983.

[16] T. L. Youd, I. M. Idriss, R. Andrus, I. Arango, G. Castro, J. Christian, R. Dobry, W. Finn, L. J. Harder, M. Hynes, K. Ishihara, J. Koester, S. Liao, W. Marcuson, G. Martin, J. Mitchell, Y. Moriwaki, M. Power, P. Robertson, R. Seed e K. I. Stokoe, "Liquefaction resistance of soils summary report from the 1996 NCEER and 1998 NCEER/NSF workshops on evaluation of liquefaction resistance of soils," Journal of Geotechnical and Geoenvironmental Engineering, vol. 127(10), p. 817-833, 2001.

[17] D. Wijewickreme, S. Sriskandakumar e P. Byrne, "Cyclic loading response of loose airpluviated Fraser River sand for validation of numerical models simulating centrifuge tests," Canadian Geotechnical Journal, vol. 42, pp. 550-561, 2005.

[18] M. Al-Tarhouni, P. Simms e S. Sivathayalan, "Cyclic behavior of reconstituted and 
desiccated-rewet tchickned gold tailings in simple shear," Canadian Geotechnical Journal, Vols. \%1 de \%21044-1060, p. 48, 2011.

[19] M. G. Jefferies e K. Been, Soil liquefaction. A critical state approach, USA and Canada: Taylor \& Francis, 2006.

[20] V. De Gennaro, J. Canou, J. C. Dupla e N. Benahmed, "Influence of loading path on the undrained behaviour of a medium loose sand," Canadian Geotechnical Journal, vol. 41, pp. 166-180, 2004.

[21] A. G. Papadimitrou e G. D. Bouckovalas, "Plasticity model for sand under small and large cyclic strains: a multiaxial formulation," Soil Dynamics and Earthquake Engineering, vol. 22, pp. 191-204, 2002.

[22] R. N. J. Azeiteiro, V. D. Marques e P. A. L. F. Coelho, "Effect of singular peaks in uniform cyclic loading on the liquefaction resistance of sand," em Second International Conference on Performance-Based Design in Earthquake Geotechnical Engineering, CD-ROM: Art. N. 6.14, Taormina, Italy, 2012.

\section{FIGURES}

a)

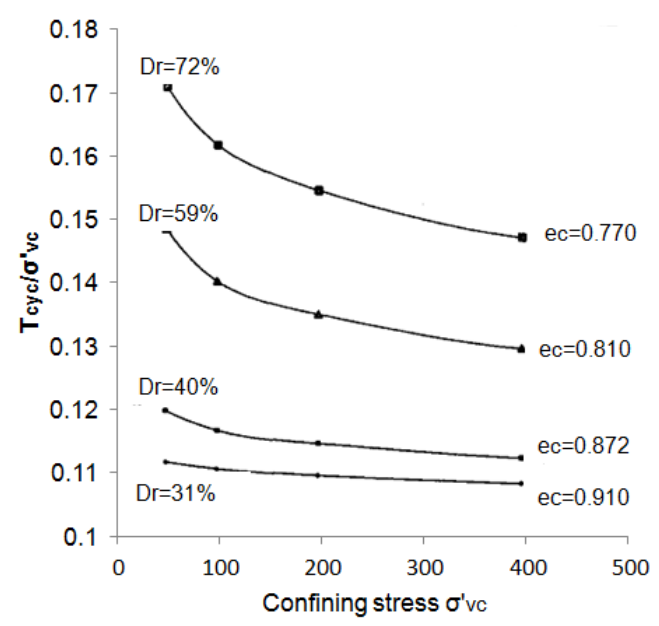

b)

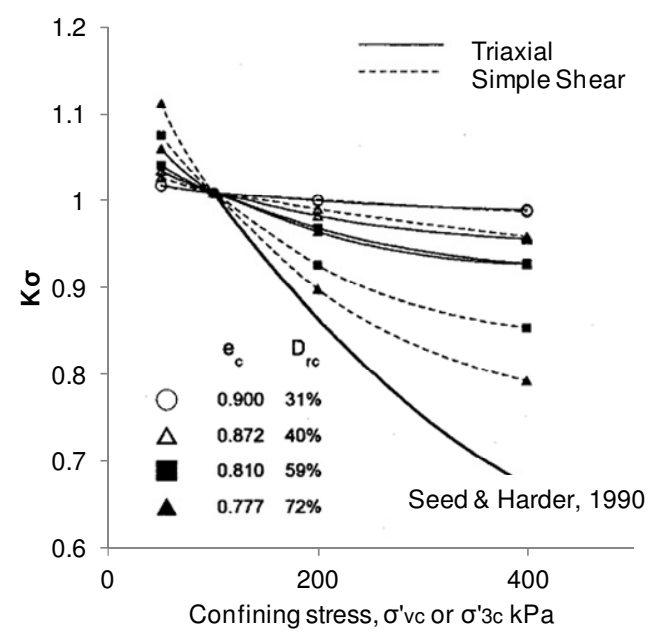

Fig.1 - Liquefaction resistance of Fraser River sand in simple shear; effect of confining stress level at different relative densities; $\mathrm{K}_{\sigma}$ under simple shear and triaxial stress conditions for Fraser Delta sand (Vaid and Sivathayalan [7]) 

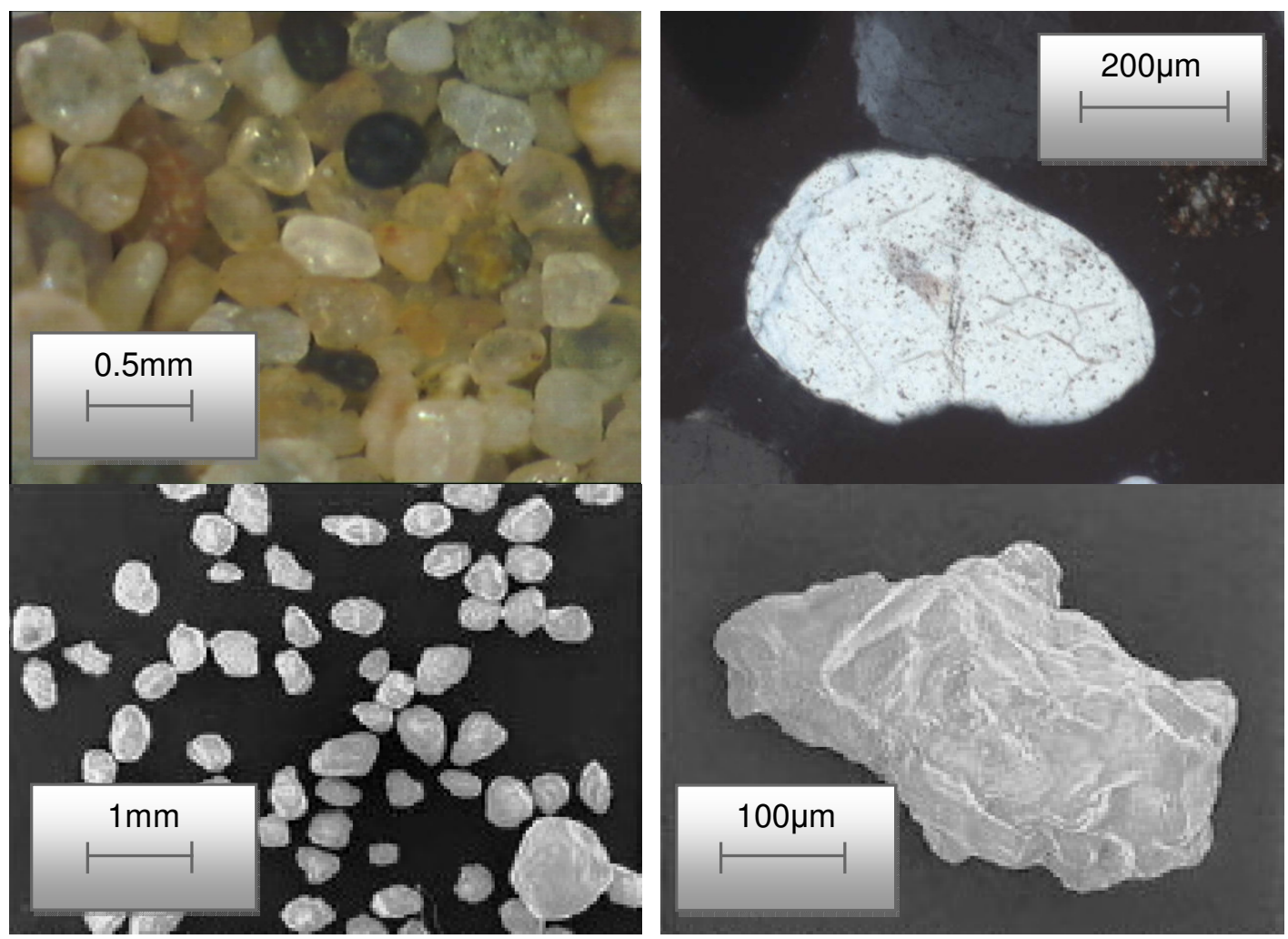

Fig. 2 - Grain shape for Algeria and Coimbra sand, from top to bottom, respectively (bottom figures from Azeiteiro et al. [22])

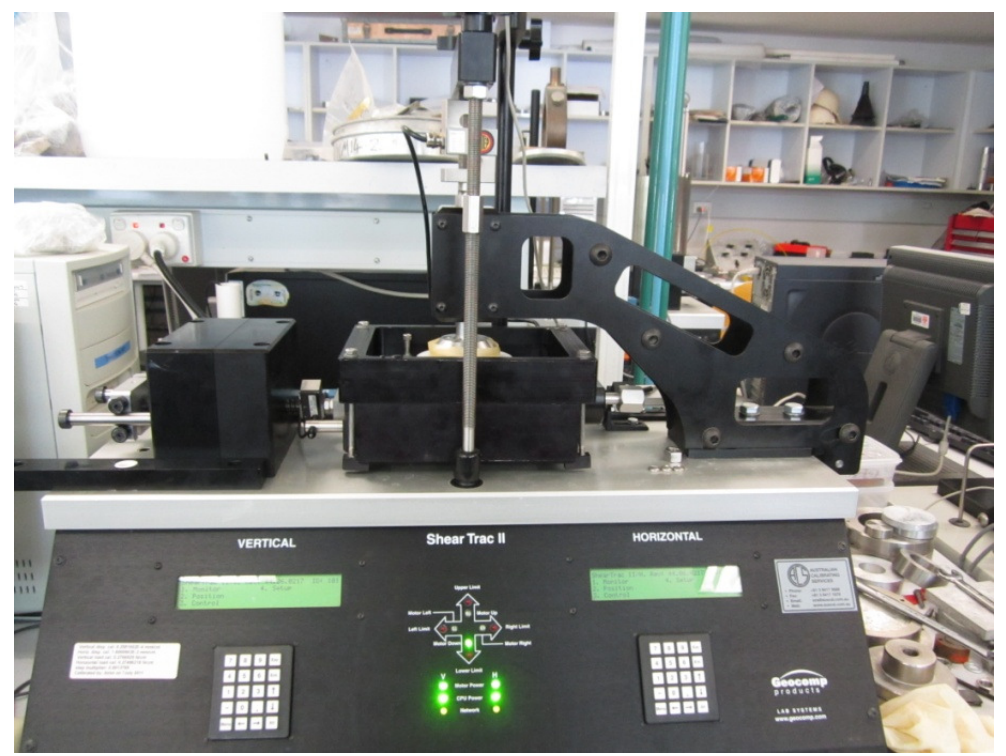

Fig. 3 - DSS device at UWA 


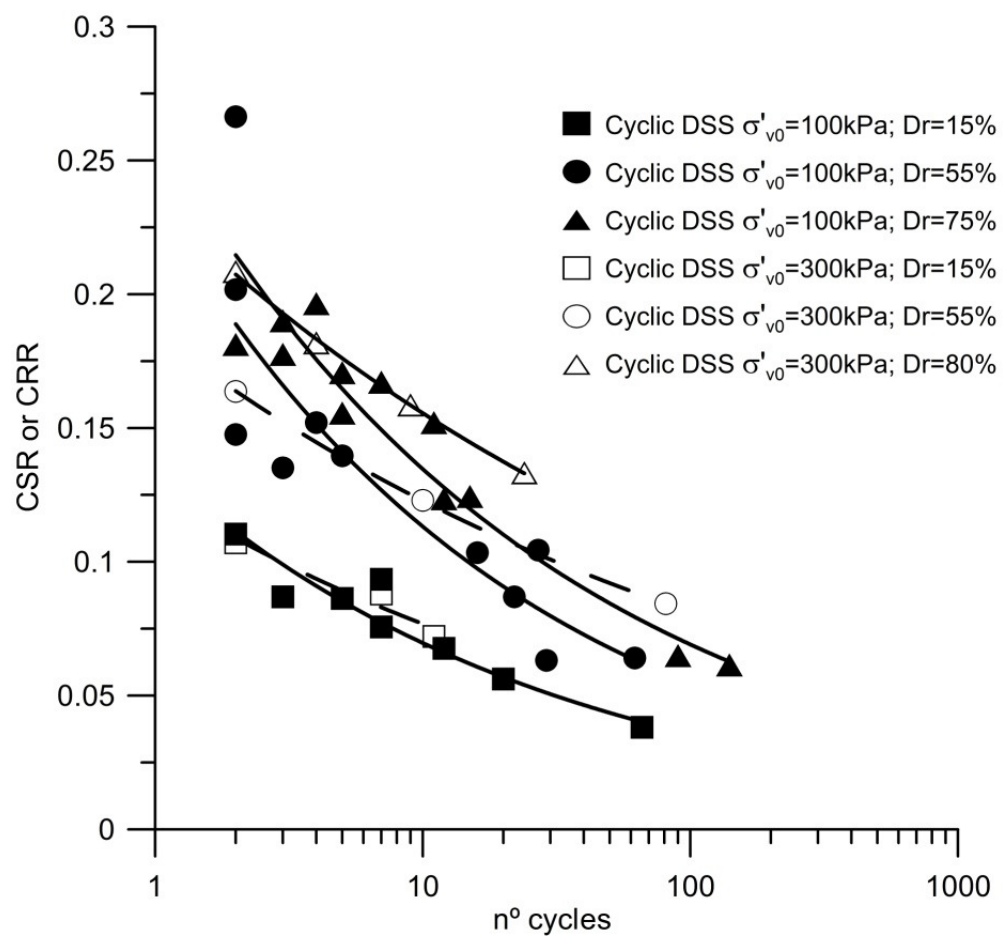

Fig.4 - Cyclic resistance curves for Algeria sand in DSS conditions (without initial static shear stress, $\alpha=0$ )

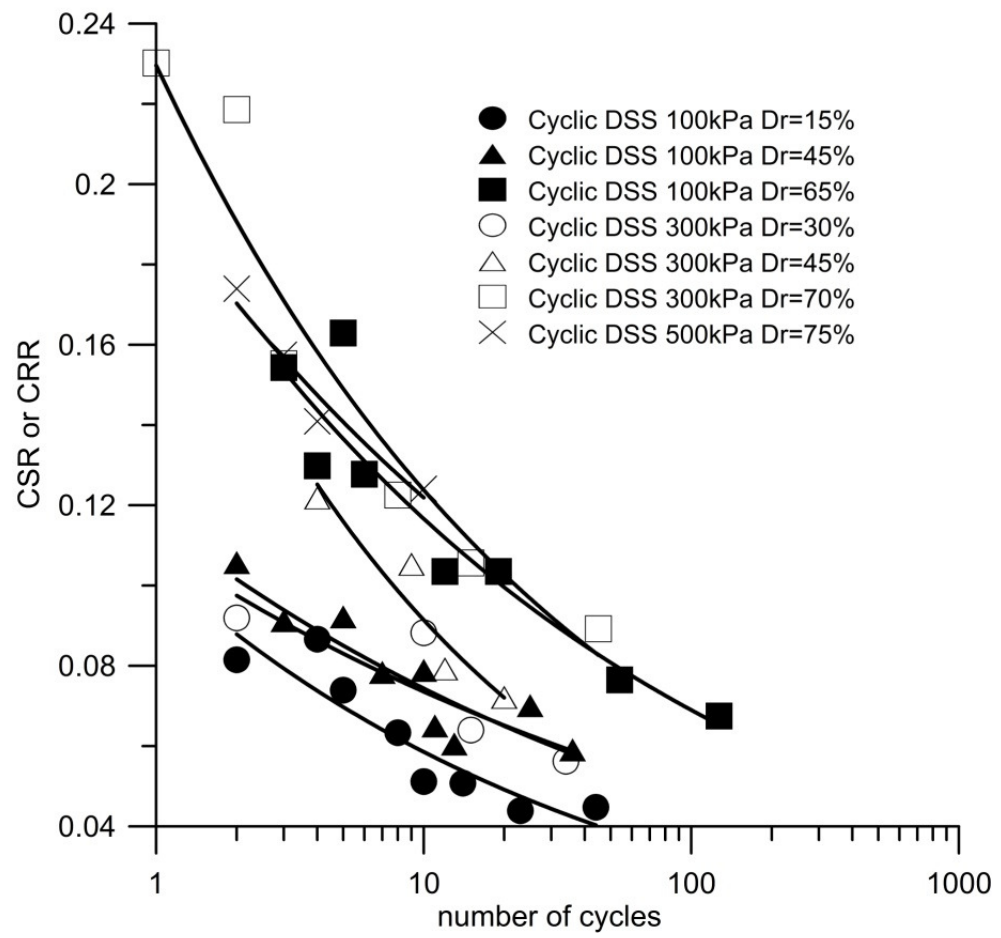

Fig.5 - Cyclic resistance curves for Coimbra sand in DSS conditions (without initial static shear stress, $\alpha=0$ ) 


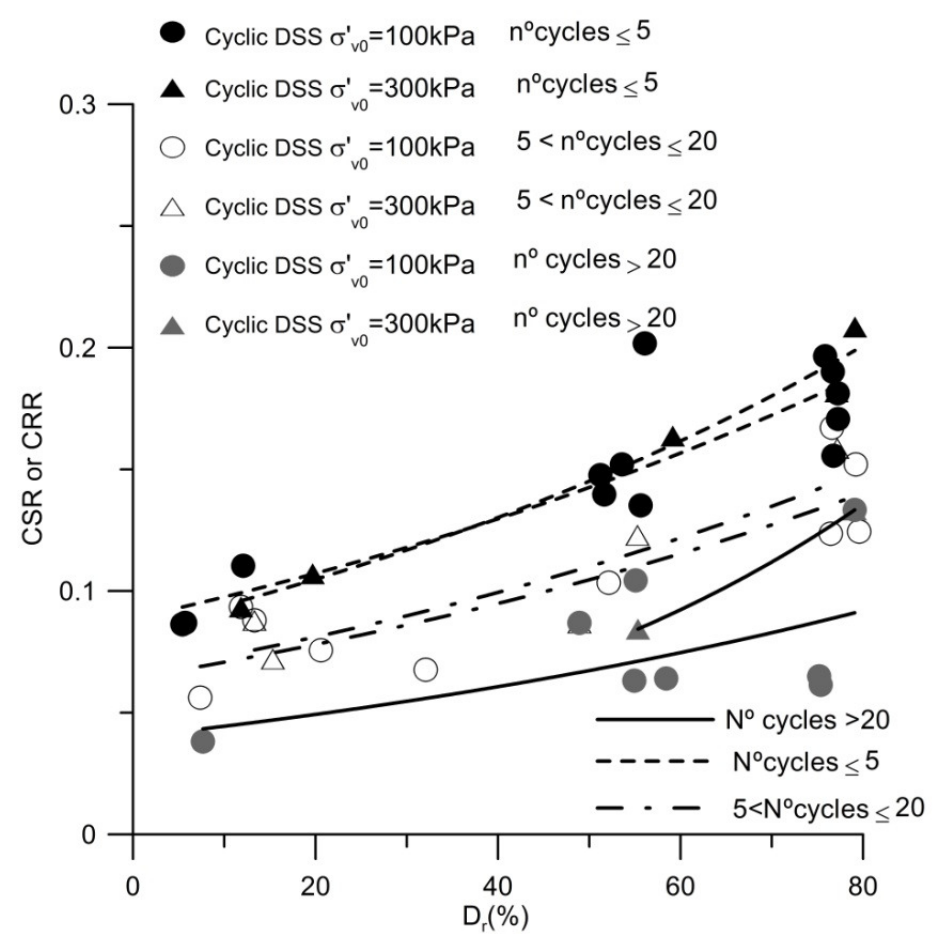

Fig.6 - Dependence of cyclic resistance on relative density for 100 and $300 \mathrm{kPa}$ of confining stress for Algeria sand

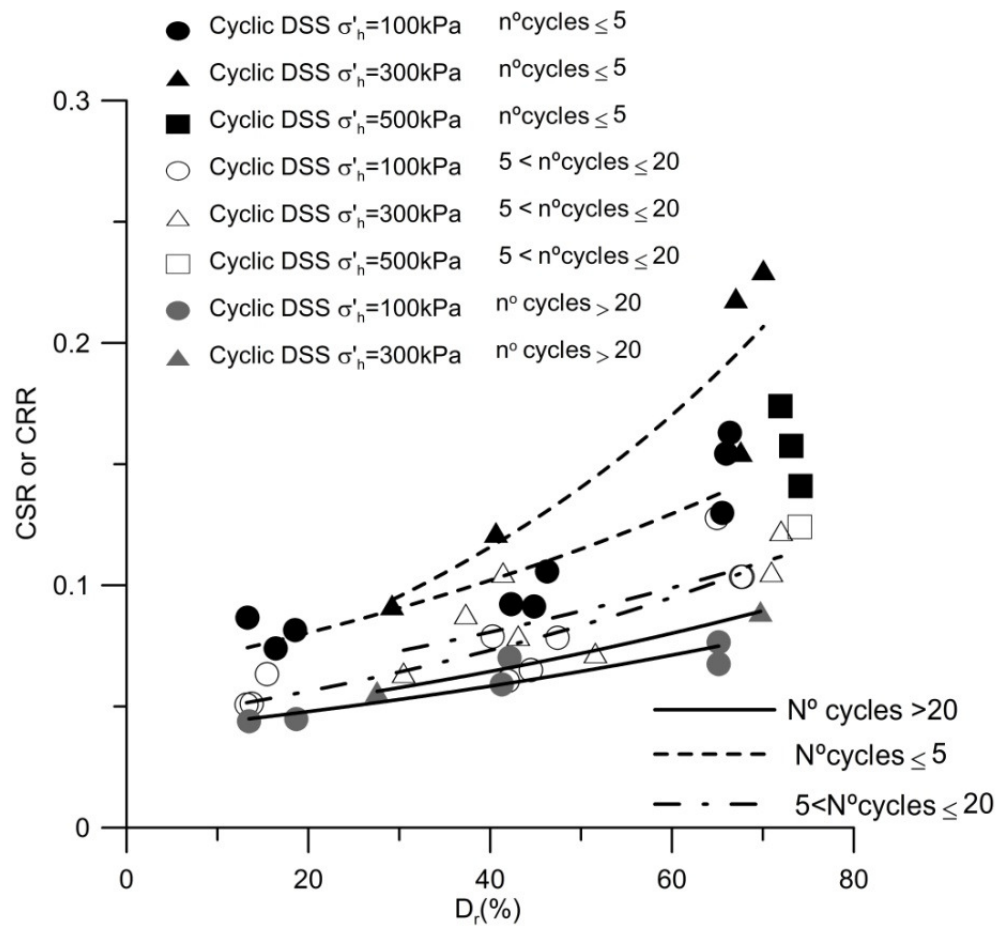

Fig.7 - Dependence of cyclic resistance on relative density for 100,300 and $500 \mathrm{kPa}$ of confining stress for Coimbra sand 

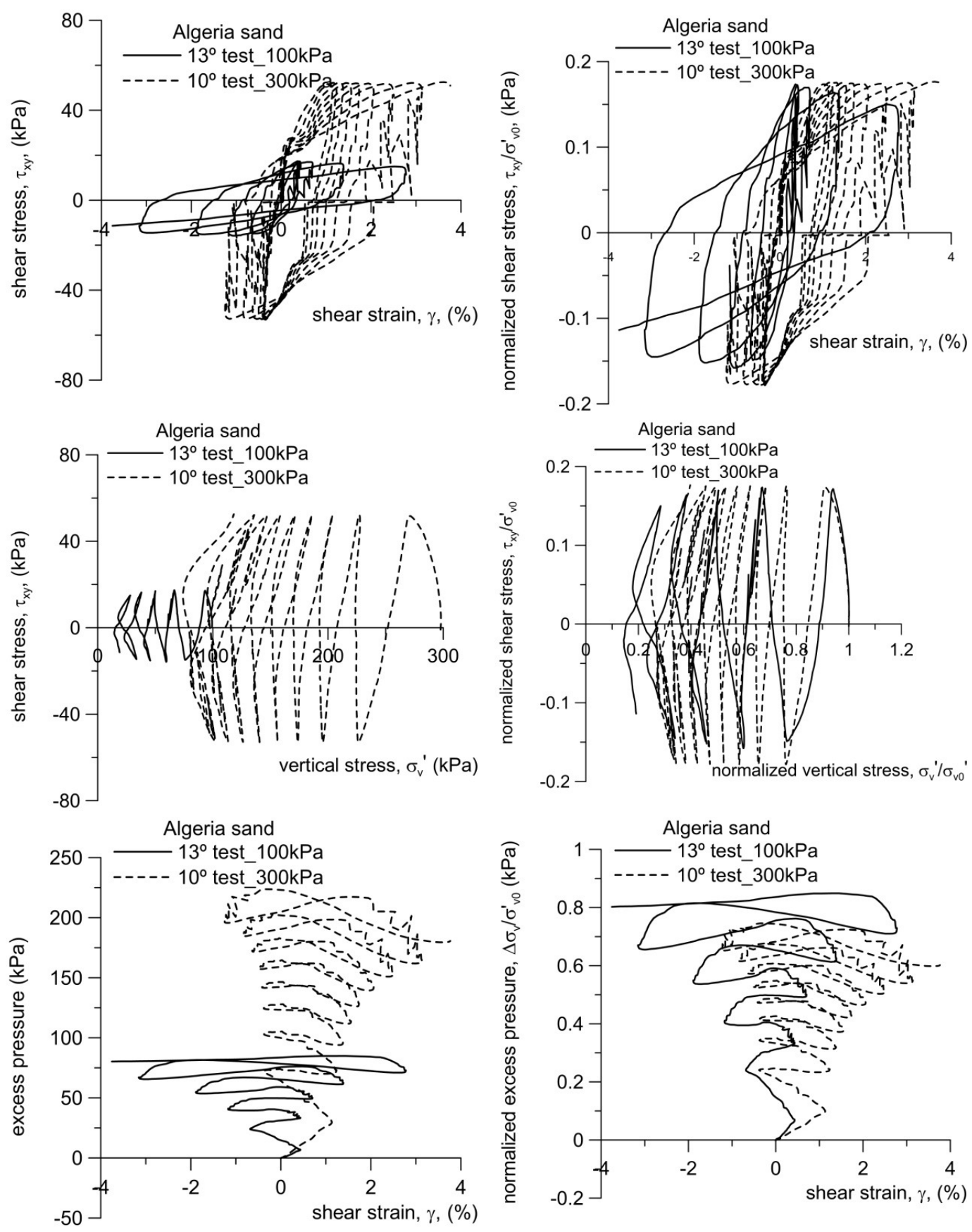

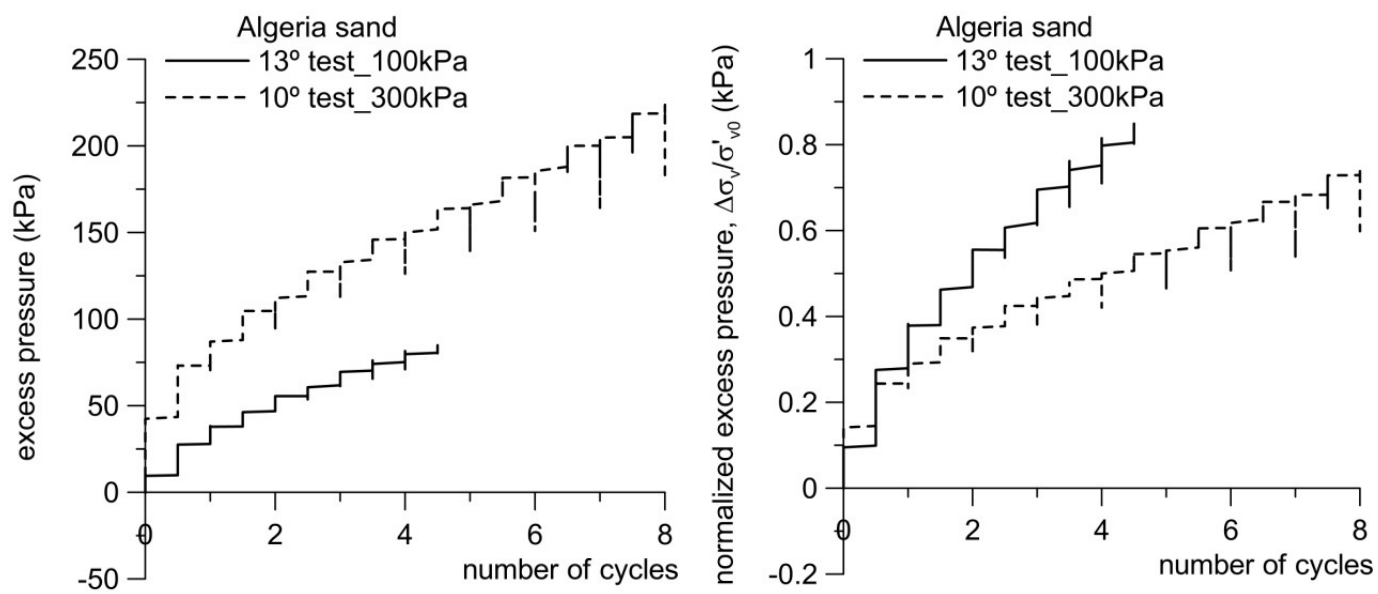

Fig. 8 - Stress-strain, stress-path, and excess pore pressure with and without normalization, from left to right respectively, for $13^{\circ}$ test_100kPa and 10 test_300kPa for Algeria sand
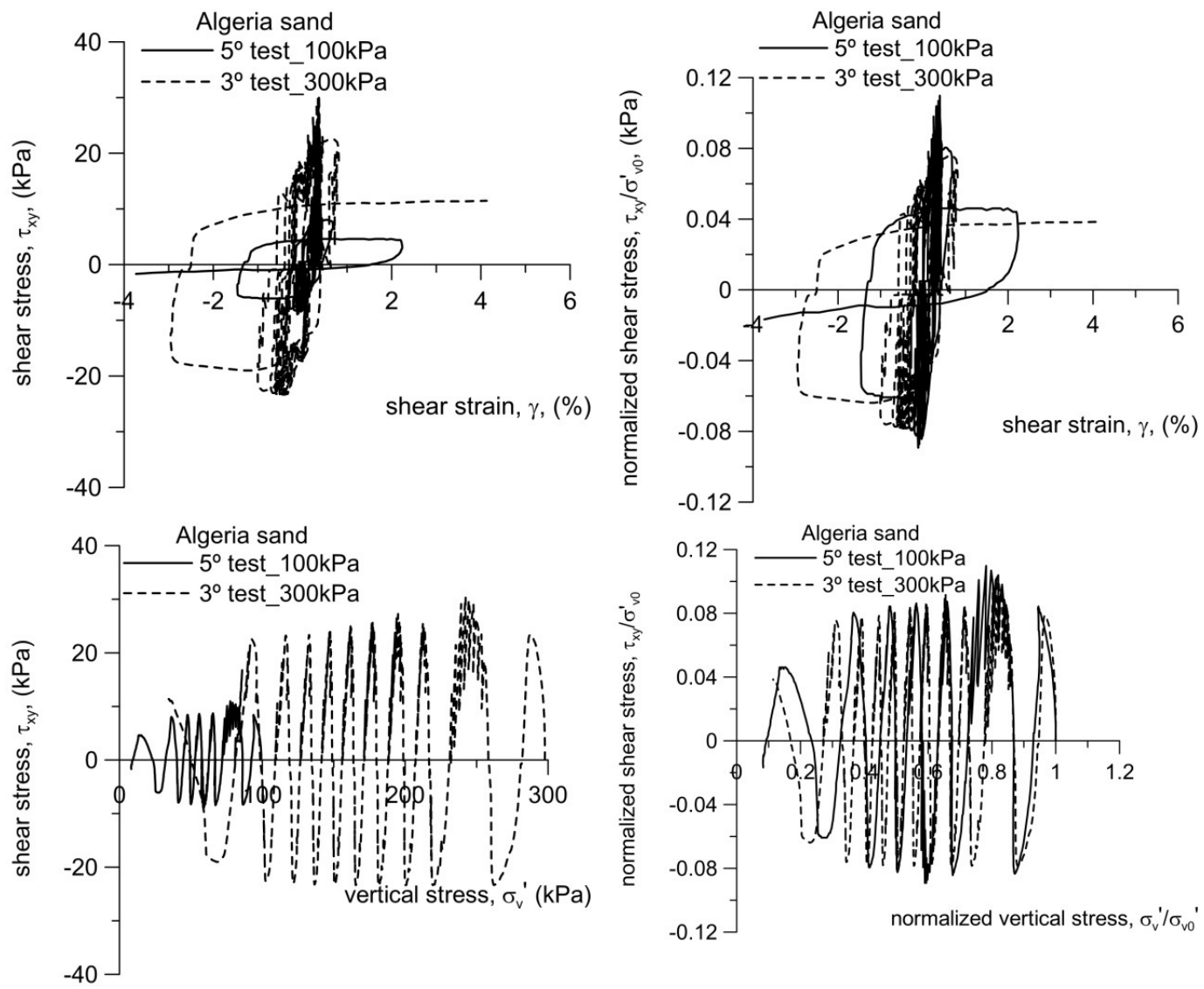

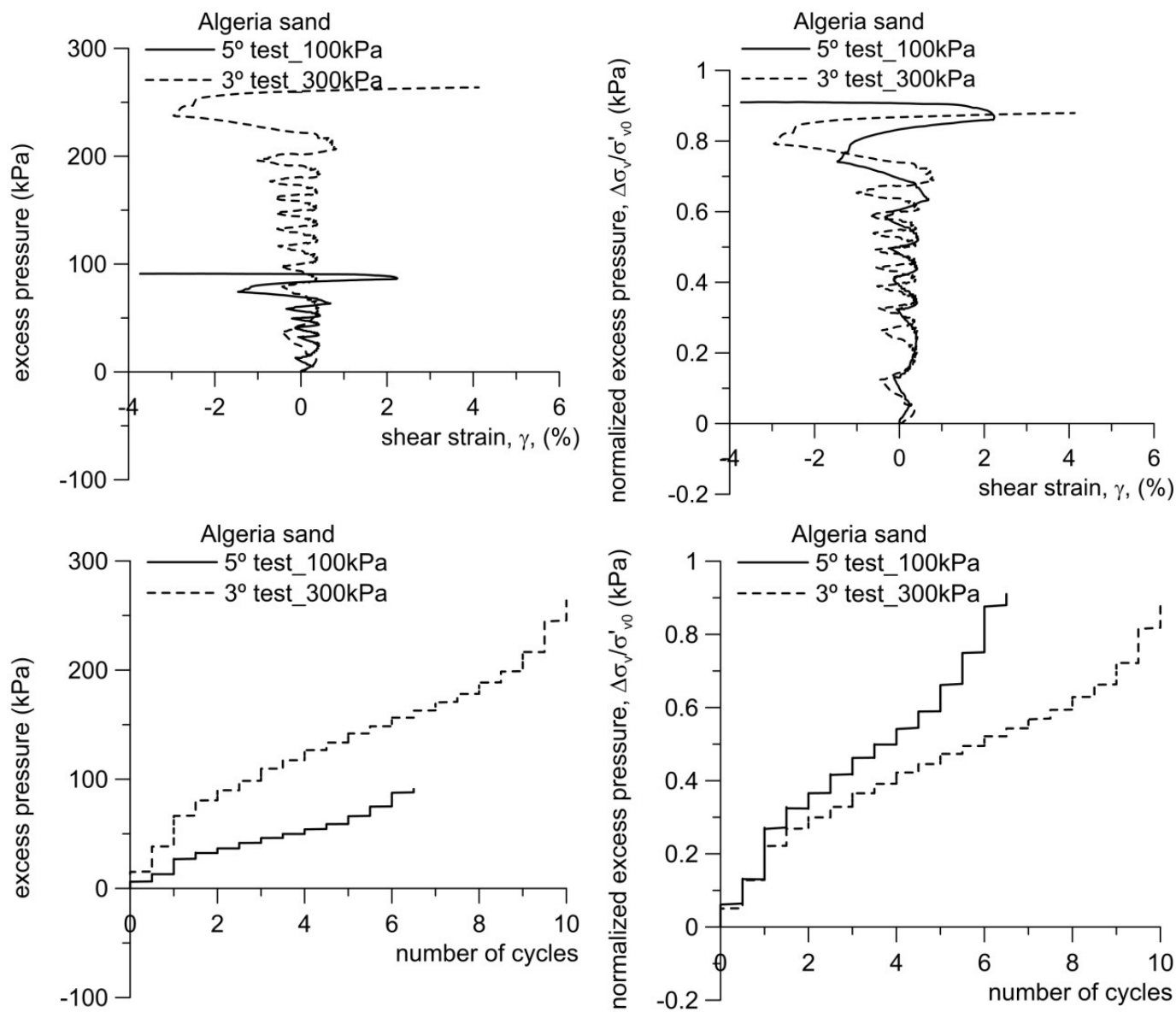

Fig.9 - Stress-strain, stress-path, and excess pore pressure with and without normalization, from left to right respectively, for $5^{\circ}$ test_100kPa and $3^{\circ}$ test_300kPa for Algeria sand
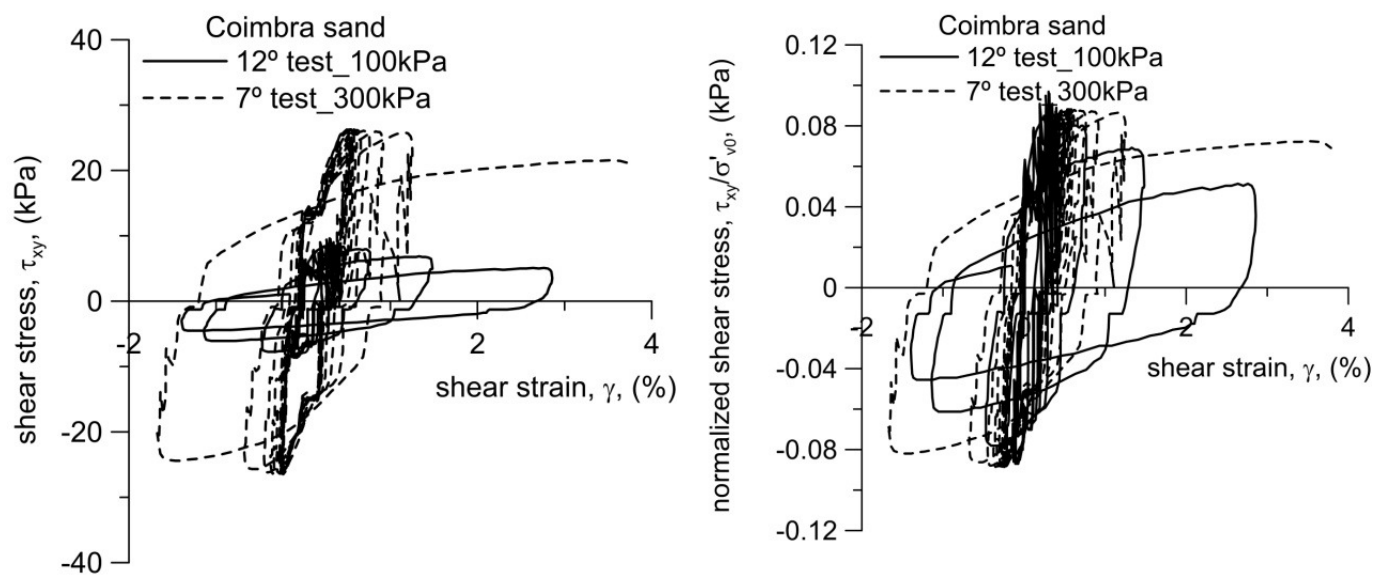

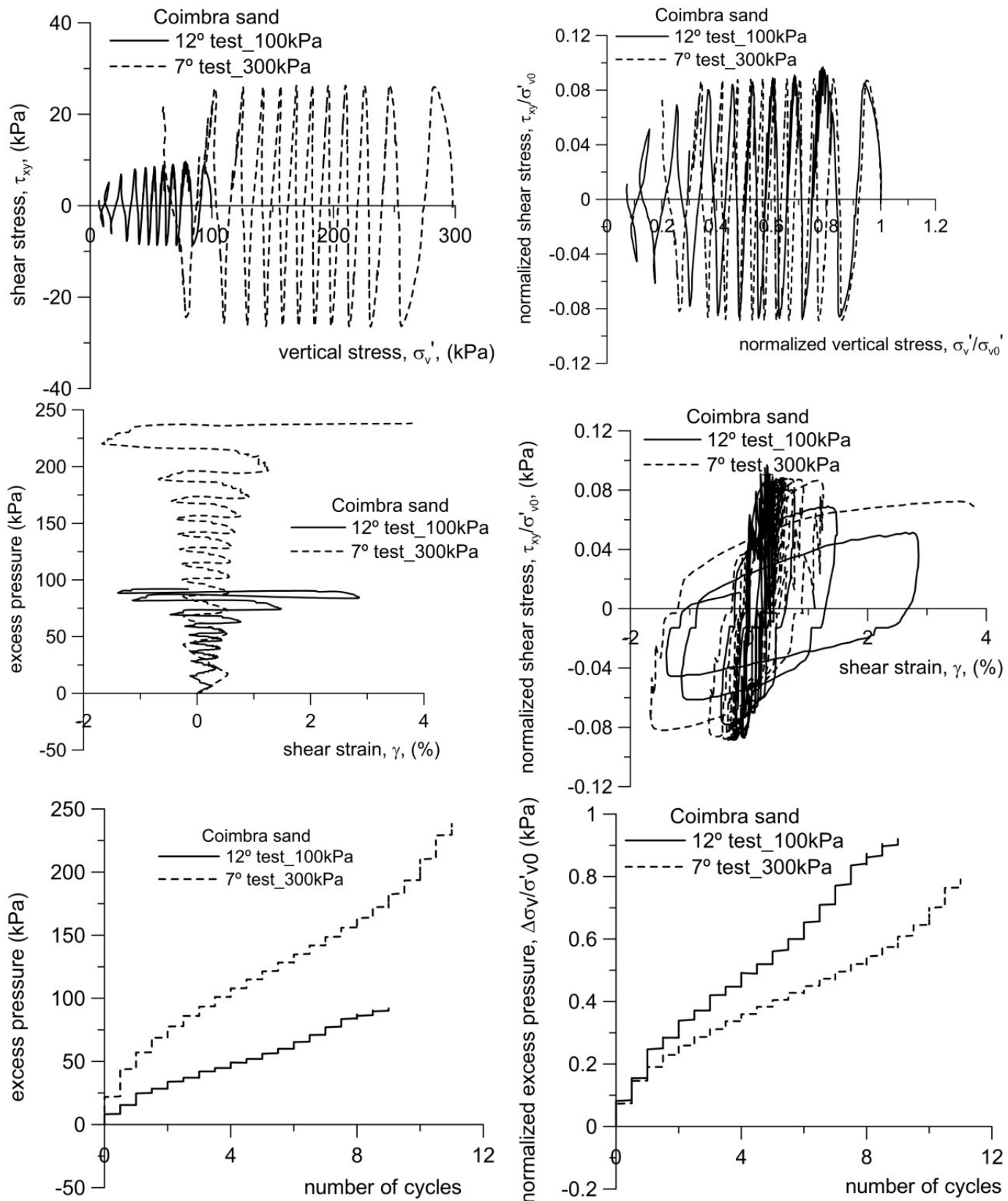

Fig 10 - Stress-strain, stress-path, and excess pore pressure with and without normalization, from left to right respectively, for $12^{\circ}$ test_100kPa and $7^{\circ}$ test_300kPa for Coimbra sand 

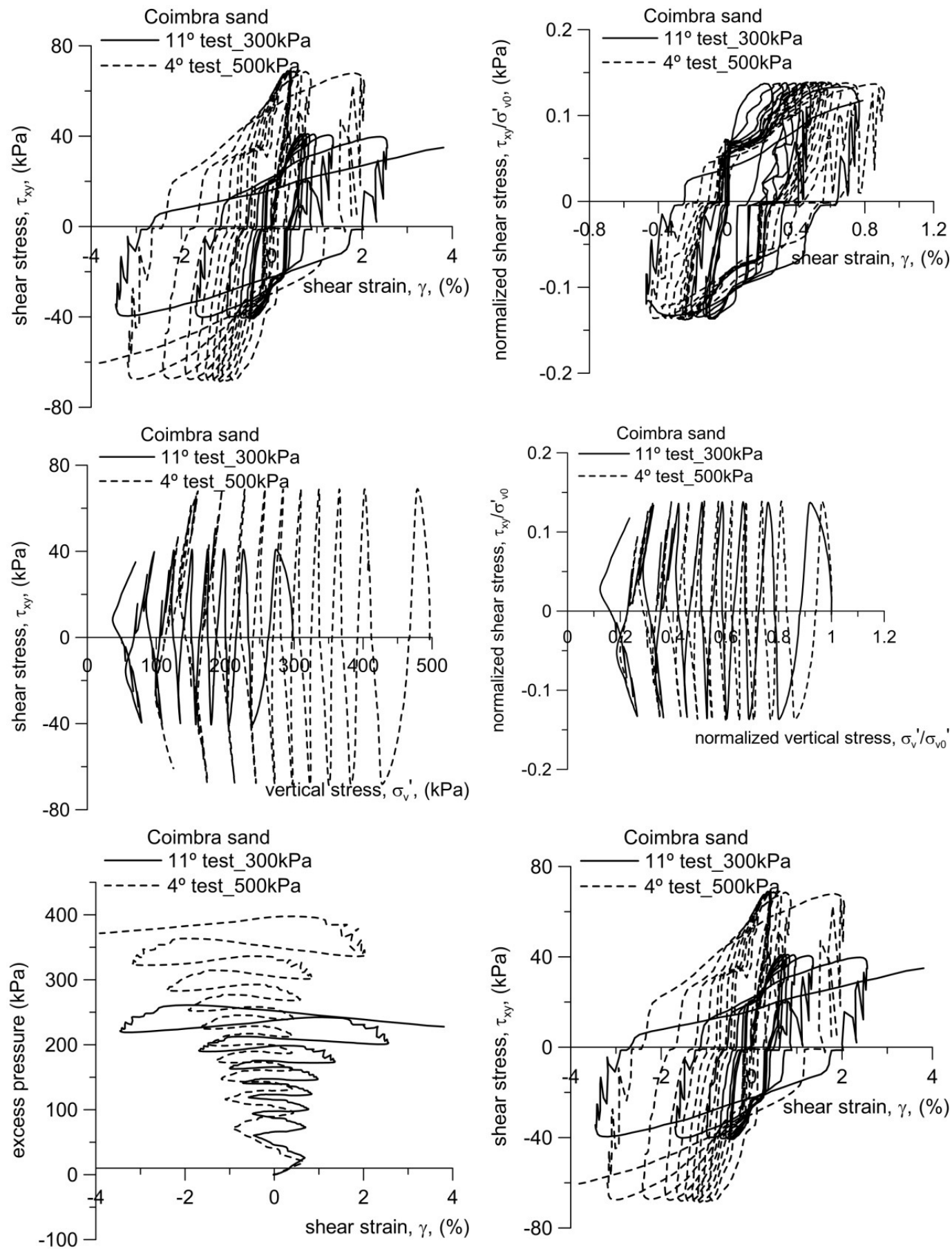

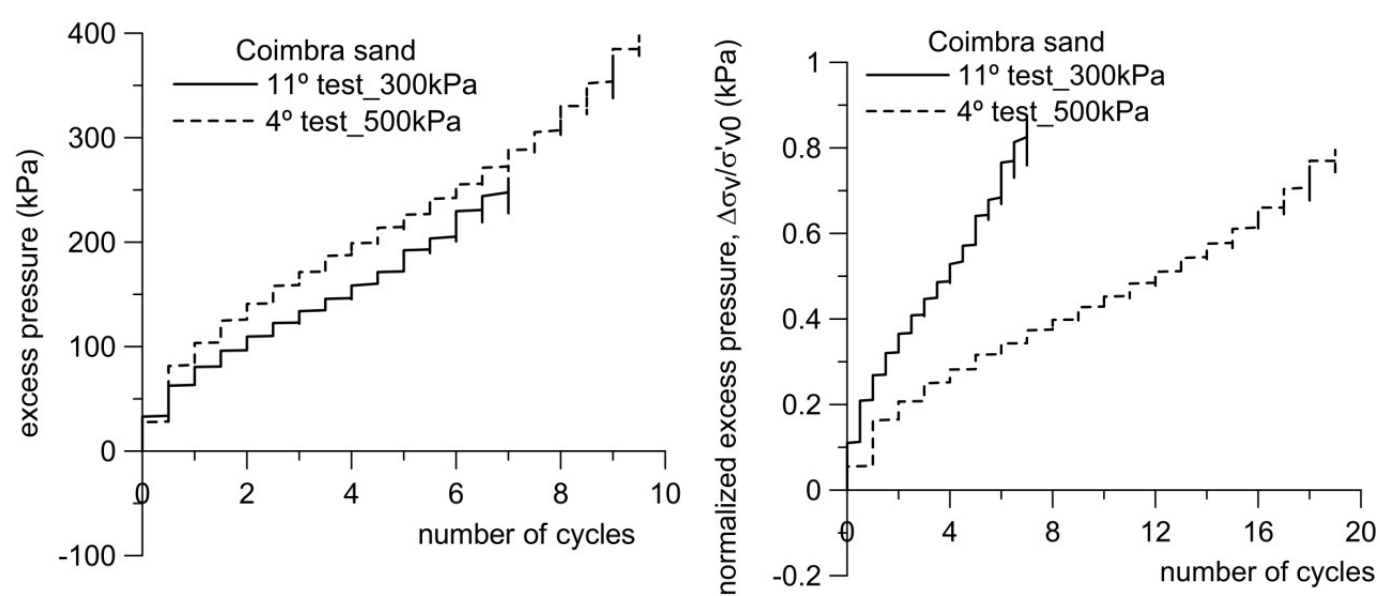

Fig.11 - Stress-strain, stress-path, and excess pore pressure with and without normalization, from left to right respectively, for $11^{\circ}$ test_300kPa and $4^{\circ}$ test_500kPa for Coimbra sand

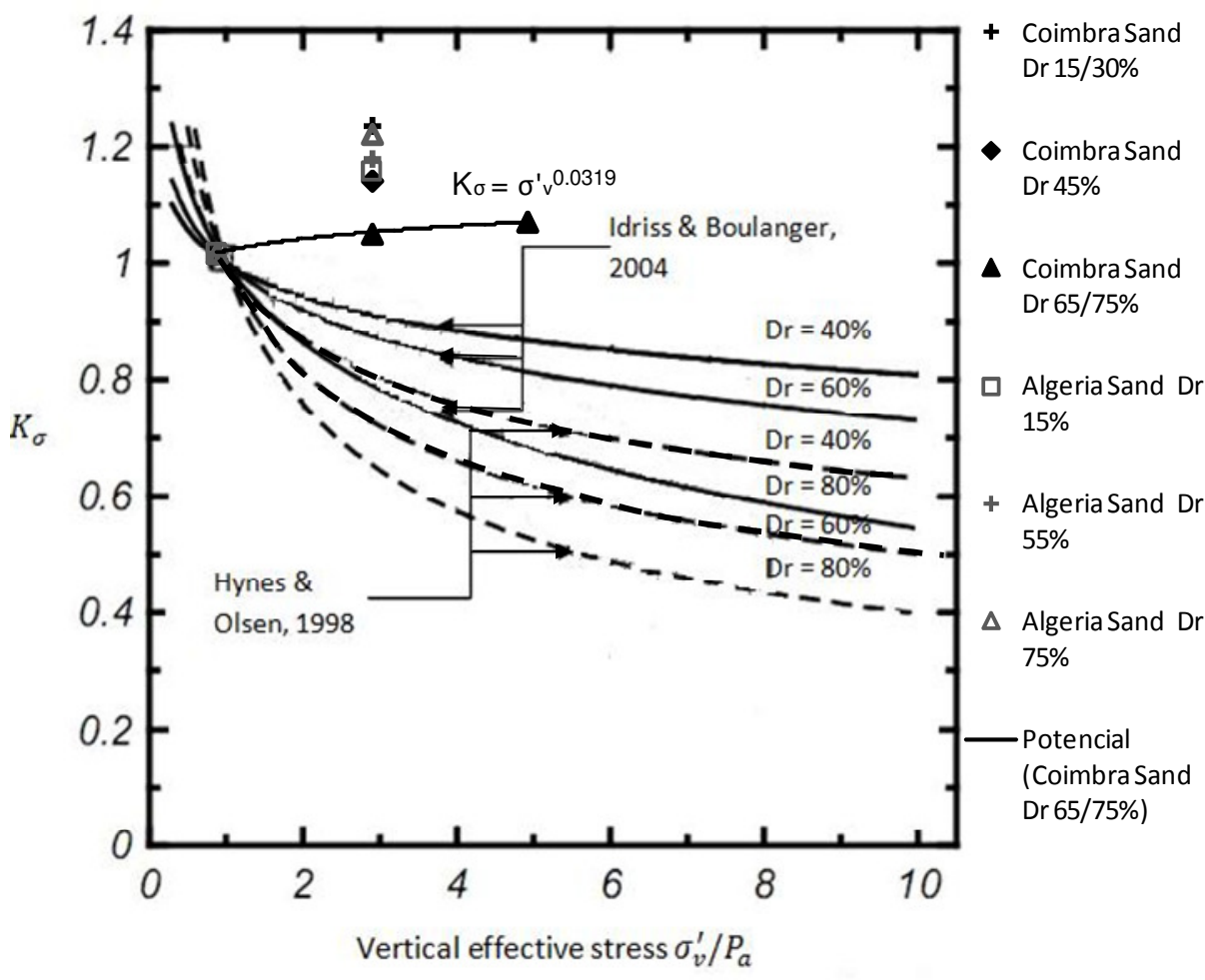

Fig.12 - Dependence of cyclic resistance on confining stress and empirical $\mathrm{K}_{\sigma}$ values for Algeria and Coimbra sand (adapted from Hynes and Olsen [2]) 


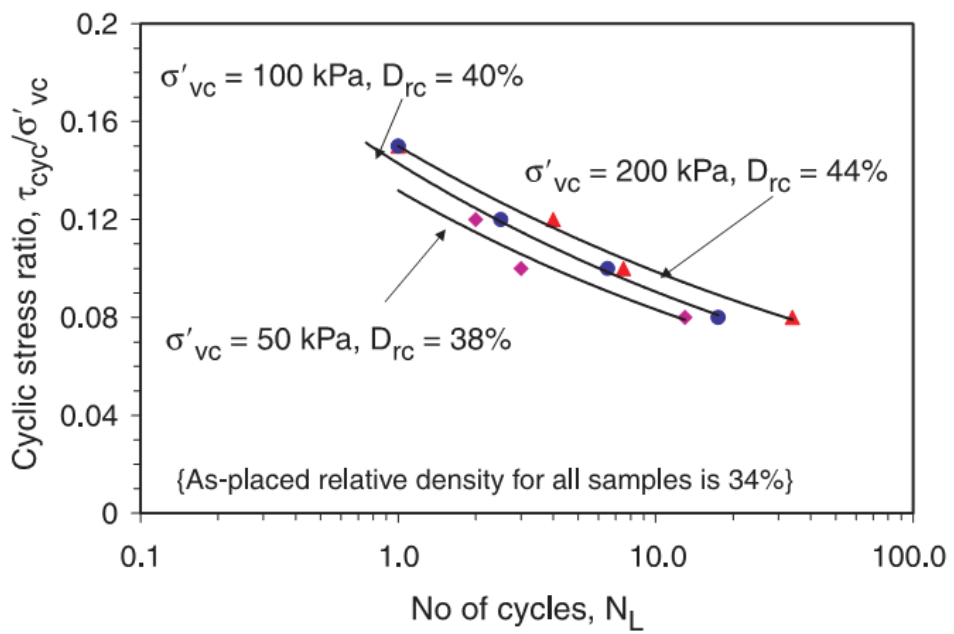

Figure 13 - Effect of stress densification on cyclic resistance of loose air-pluviated sand (Wijewickreme et al.[17])

Table 1 List of tests performed with cyclic DSS device, ordered by relative density $\left(\mathrm{D}_{\mathrm{r}}\right)$

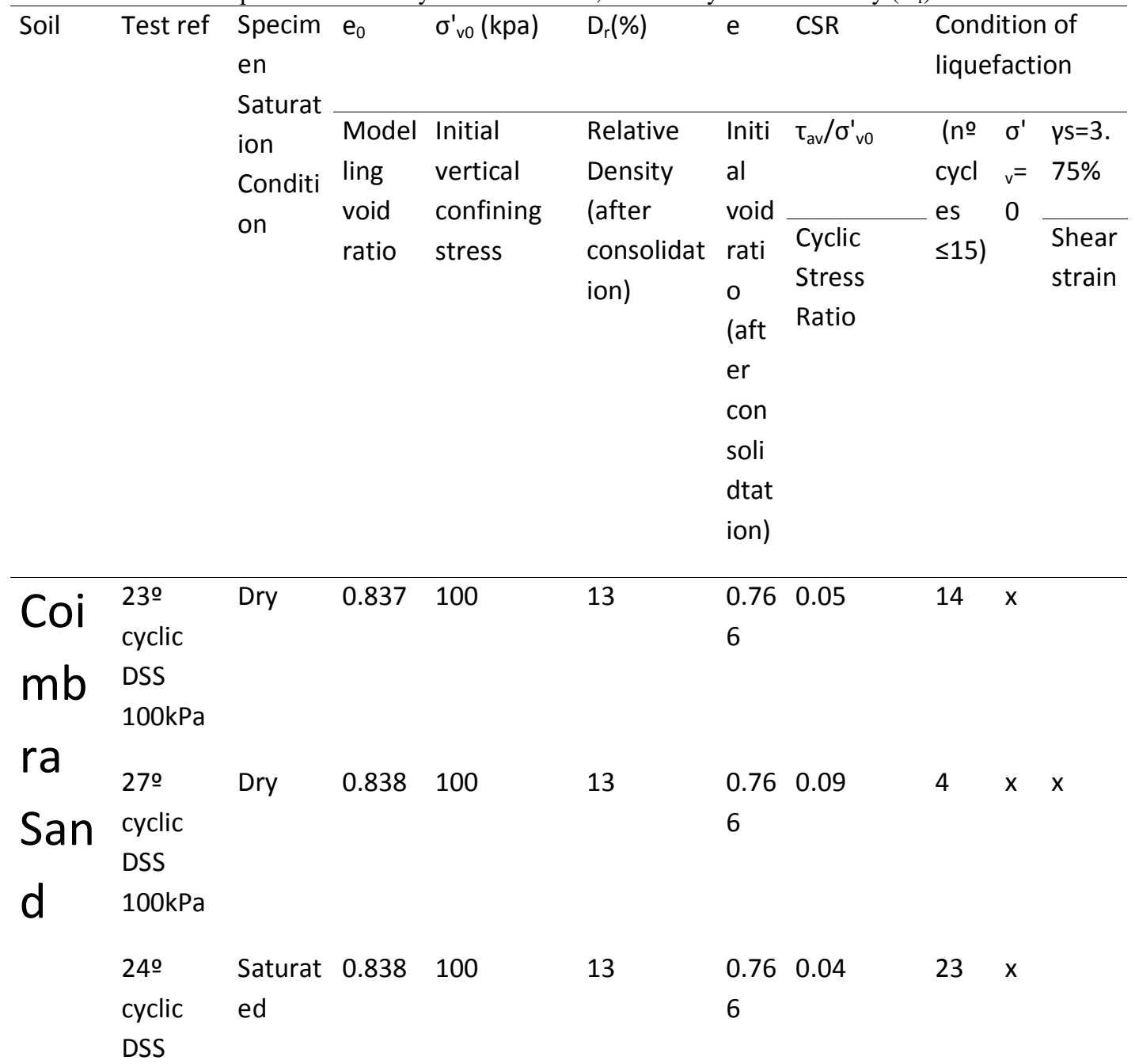




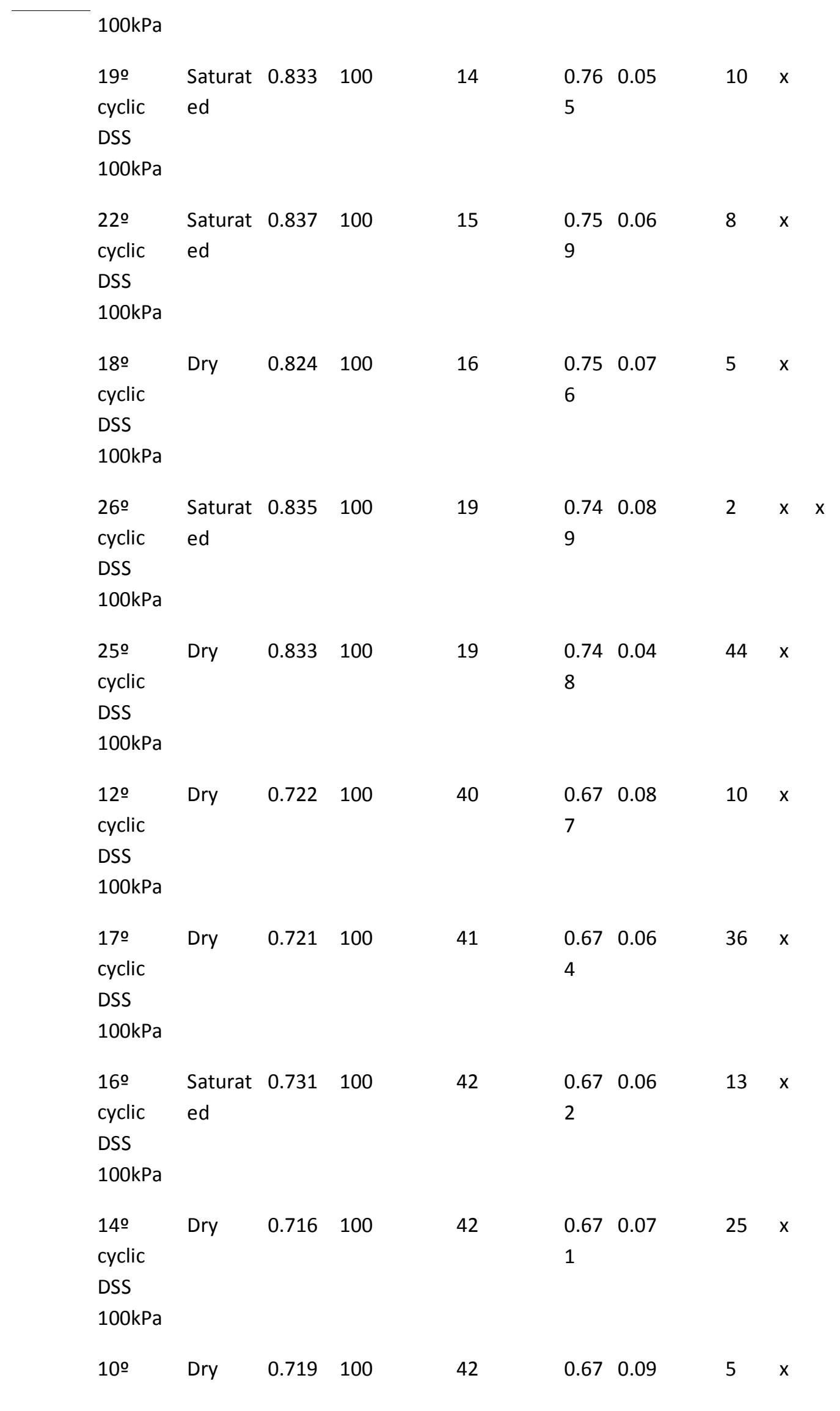


cyclic

DSS

$100 \mathrm{kPa}$

15ㅇ Saturat $0.726 \quad 100$

cyclic ed

DSS

$100 \mathrm{kPa}$

$110 \quad$ Saturat $0.727 \quad 100$

cyclic ed

DSS

$100 \mathrm{kPa}$

28 o Saturat $0.716 \quad 100$

cyclic ed

DSS

$100 \mathrm{kPa}$

13으 Saturat 0.716100

cyclic ed

DSS

$100 \mathrm{kPa}$

8o cyclic Dry 0.626100

DSS

$100 \mathrm{kPa}$

3o cyclic Dry $0.621 \quad 100$

DSS

$100 \mathrm{kPa}$

40 cyclic Saturat $0.627 \quad 100$

DSS ed

$100 \mathrm{kPa}$

9o cyclic Saturat $0.631 \quad 100$

DSS ed

$100 \mathrm{kPa}$

2o cyclic Saturat 0.625100

DSS

ed

$100 \mathrm{kPa}$

10 cyclic Dry 0.629100

DSS

$100 \mathrm{kPa}$
0

44

$0.66 \quad 0.07$

$11 \mathrm{x}$

3

45

0.660 .09

$3 \times x$

2

46

$0.65 \quad 0.11$

$2 \times x$

7

47

0.650 .08

4

65

6

$\begin{array}{llll}65 & 0.59 & 0.07 & 127 \times\end{array}$

5

65

0.590 .08

5

$\begin{array}{lllll}66 & 0.59 & 0.13 & 4 & x\end{array}$

4

$\begin{array}{llll}0.59 & 0.15 & 3 & x\end{array}$

2

$\begin{array}{llll}0.59 & 0.16 & 5 & x\end{array}$

1 


\begin{tabular}{|c|c|c|c|c|c|c|c|c|}
\hline $\begin{array}{l}\text { 60 cyclic } \\
\text { DSS } \\
100 \mathrm{kPa}\end{array}$ & $\begin{array}{l}\text { Saturat } \\
\text { ed }\end{array}$ & 0.621 & 100 & 68 & $\begin{array}{l}0.58 \\
7\end{array}$ & 0.10 & 12 & $x$ \\
\hline $\begin{array}{l}50 \text { cyclic } \\
\text { DSS } \\
100 \mathrm{kPa}\end{array}$ & Dry & 0.628 & 100 & 68 & $\begin{array}{l}0.58 \\
6\end{array}$ & 0.10 & 19 & $x$ \\
\hline $\begin{array}{l}\text { 3o cyclic } \\
\text { DSS } \\
300 \mathrm{kPa}\end{array}$ & $\begin{array}{l}\text { Saturat } \\
\text { ed }\end{array}$ & 0.836 & 300 & 28 & $\begin{array}{l}0.71 \\
9\end{array}$ & 0.06 & 34 & \\
\hline $\begin{array}{l}\text { 10 cyclic } \\
\text { DSS } \\
300 \mathrm{kPa}\end{array}$ & $\begin{array}{l}\text { Saturat } \\
\text { ed }\end{array}$ & 0.834 & 300 & 29 & $\begin{array}{l}0.71 \\
4\end{array}$ & 0.09 & 2 & \\
\hline $\begin{array}{l}20 \text { cyclic } \\
\text { DSS } \\
300 \mathrm{kPa}\end{array}$ & $\begin{array}{l}\text { Saturat } \\
\text { ed }\end{array}$ & 0.830 & 300 & 30 & $\begin{array}{l}0.70 \\
9\end{array}$ & 0.06 & 15 & \\
\hline $\begin{array}{l}60 \text { cyclic } \\
\text { DSS } \\
300 \mathrm{kPa}\end{array}$ & $\begin{array}{l}\text { Saturat } \\
\text { ed }\end{array}$ & 0.754 & 300 & 37 & $\begin{array}{l}0.68 \\
7\end{array}$ & 0.09 & 10 & \\
\hline $\begin{array}{l}\text { 40 cyclic } \\
\text { DSS } \\
300 \mathrm{kPa}\end{array}$ & $\begin{array}{l}\text { Saturat } \\
\text { ed }\end{array}$ & 0.728 & 300 & 41 & $\begin{array}{l}0.67 \\
6\end{array}$ & 0.12 & 4 & \\
\hline $\begin{array}{l}50 \text { cyclic } \\
\text { DSS } \\
300 \mathrm{kPa}\end{array}$ & $\begin{array}{l}\text { Saturat } \\
\text { ed }\end{array}$ & 0.726 & 300 & 41 & $\begin{array}{l}0.67 \\
3\end{array}$ & 0.11 & 9 & \\
\hline $\begin{array}{l}\text { 70 cyclic } \\
\text { DSS } \\
300 \mathrm{kPa}\end{array}$ & $\begin{array}{l}\text { Saturat } \\
\text { ed }\end{array}$ & 0.725 & 300 & 43 & $\begin{array}{l}0.66 \\
8\end{array}$ & 0.08 & 12 & \\
\hline $\begin{array}{l}140 \\
\text { cyclic } \\
\text { DSS } \\
300 \mathrm{kPa}\end{array}$ & $\begin{array}{l}\text { Saturat } \\
\text { ed }\end{array}$ & 0.727 & 300 & 52 & $\begin{array}{l}0.64 \\
0\end{array}$ & 0.07 & 20 & \\
\hline $\begin{array}{l}\text { 9o cyclic } \\
\text { DSS } \\
300 \mathrm{kPa}\end{array}$ & $\begin{array}{l}\text { Saturat } \\
\text { ed }\end{array}$ & 0.634 & 300 & 67 & $\begin{array}{l}0.58 \\
9\end{array}$ & 0.22 & 2 & \\
\hline $\begin{array}{l}100 \\
\text { cyclic } \\
\text { DSS }\end{array}$ & $\begin{array}{l}\text { Saturat } \\
\text { ed }\end{array}$ & 0.636 & 300 & 68 & $\begin{array}{l}0.58 \\
7\end{array}$ & 0.16 & 3 & \\
\hline
\end{tabular}




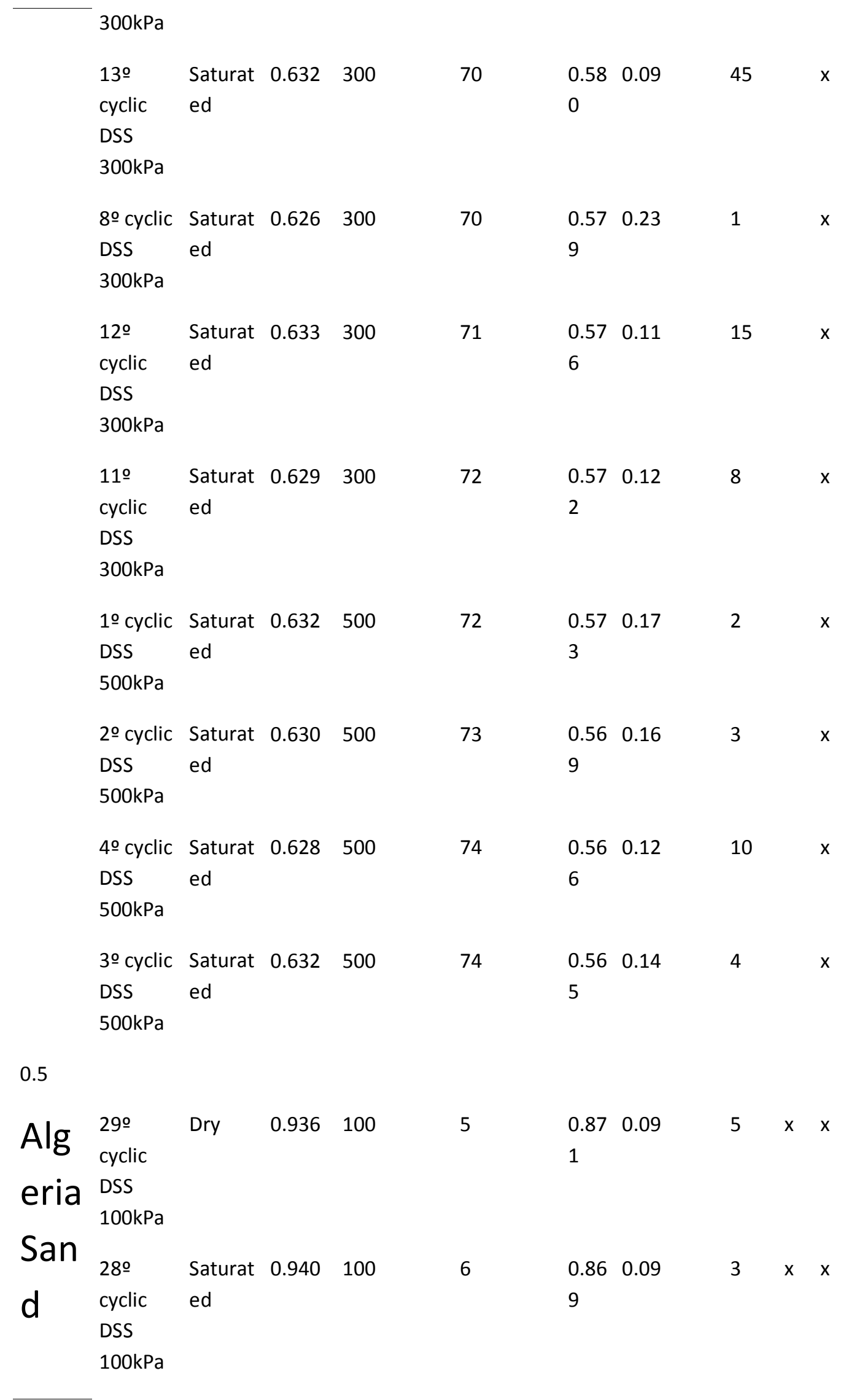




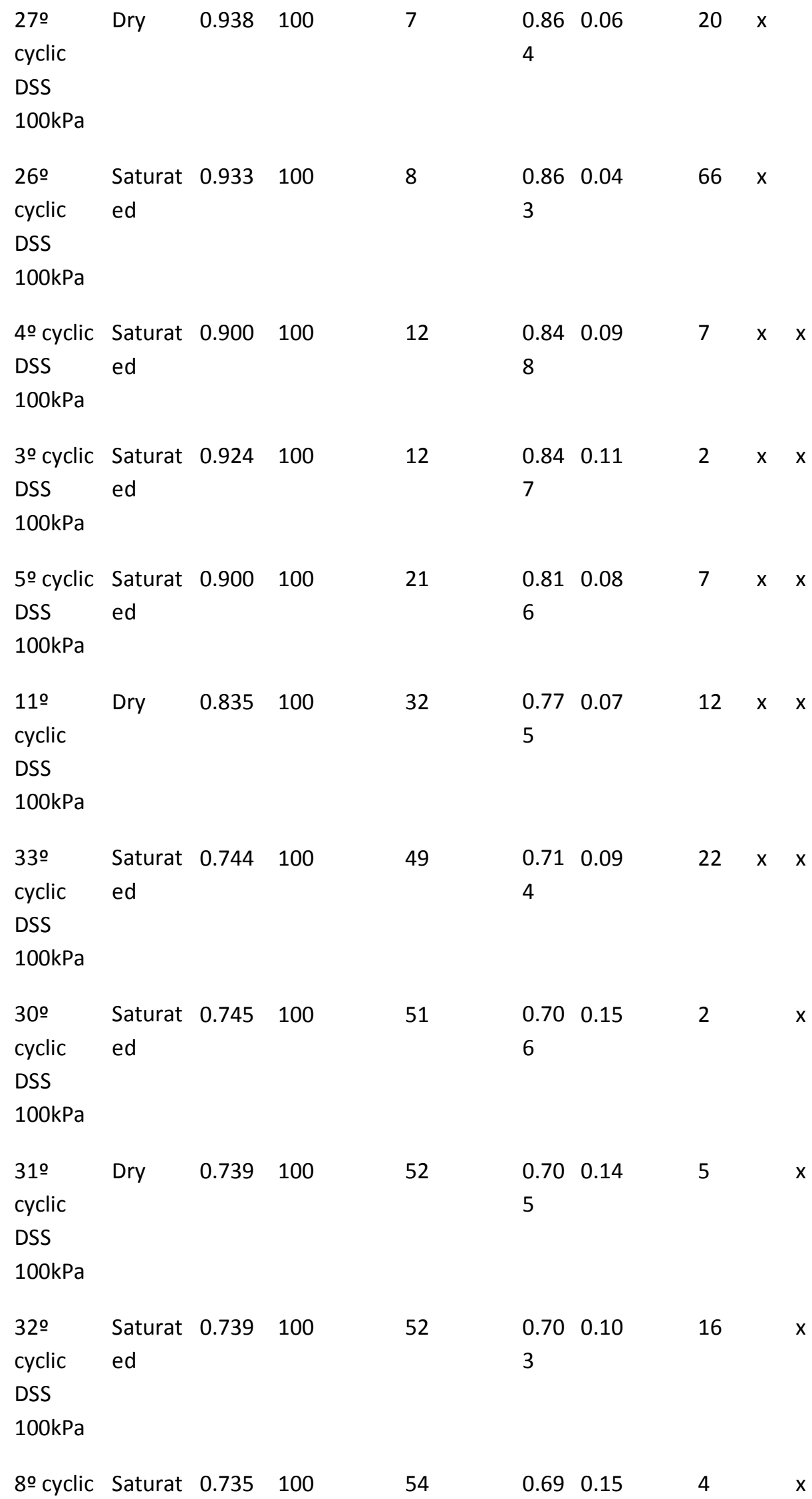




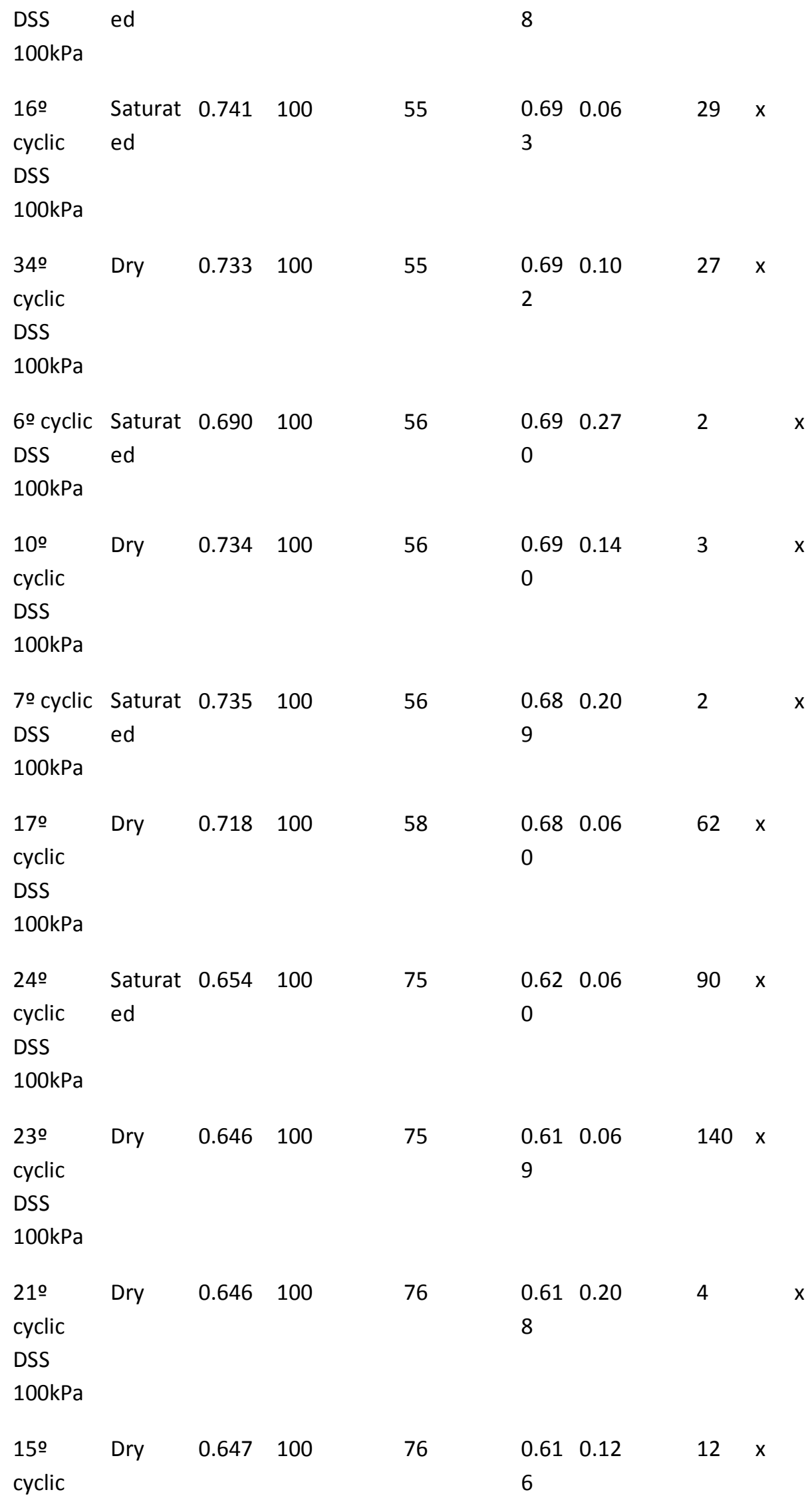

DSS

$100 \mathrm{kPa}$

15o $\quad$ Dry $\quad 0.647 \quad 100$

cyclic

76

$\begin{array}{ll}0.61 & 0.20\end{array}$

4

$\mathrm{x}$ 8 


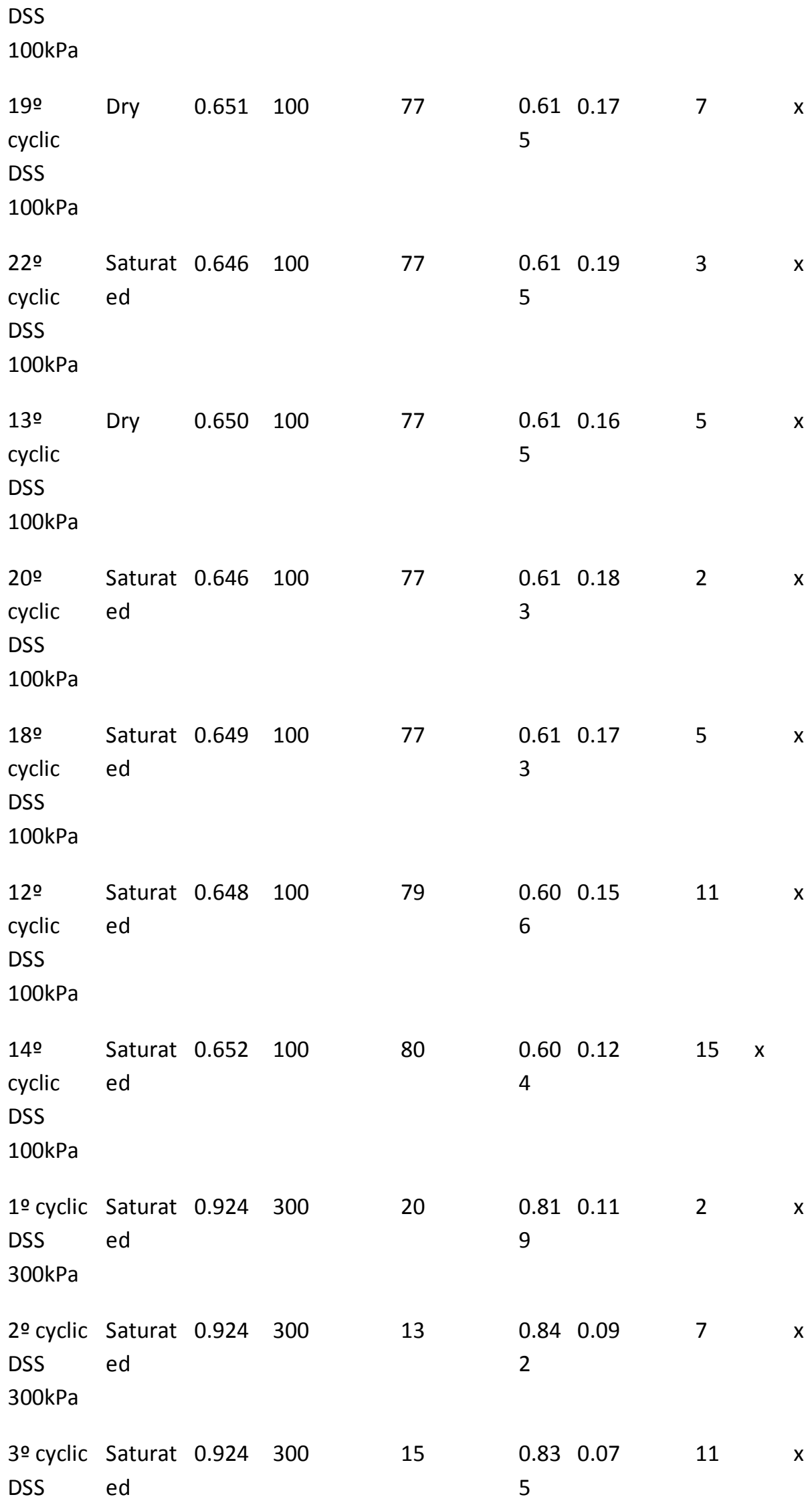




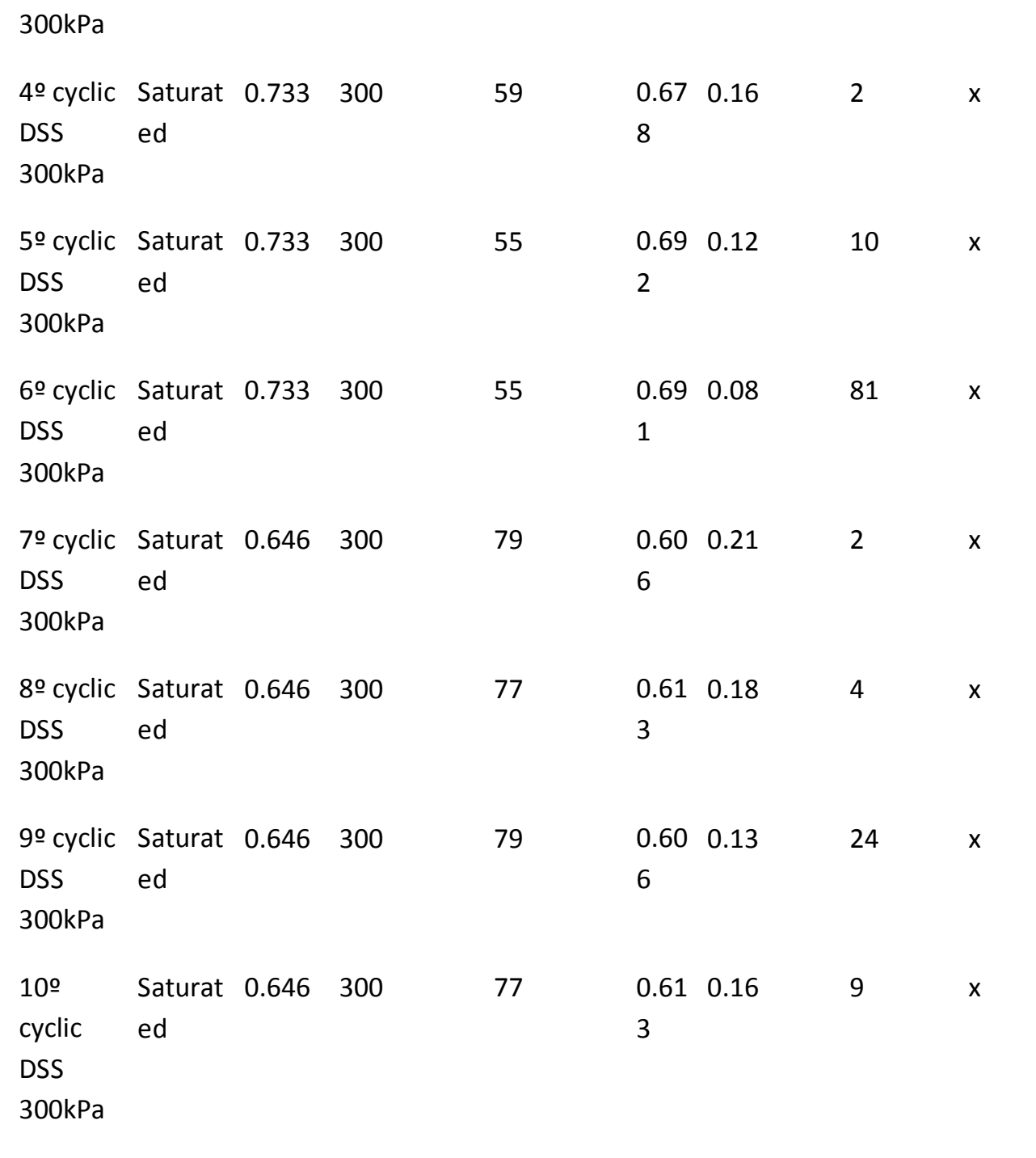

